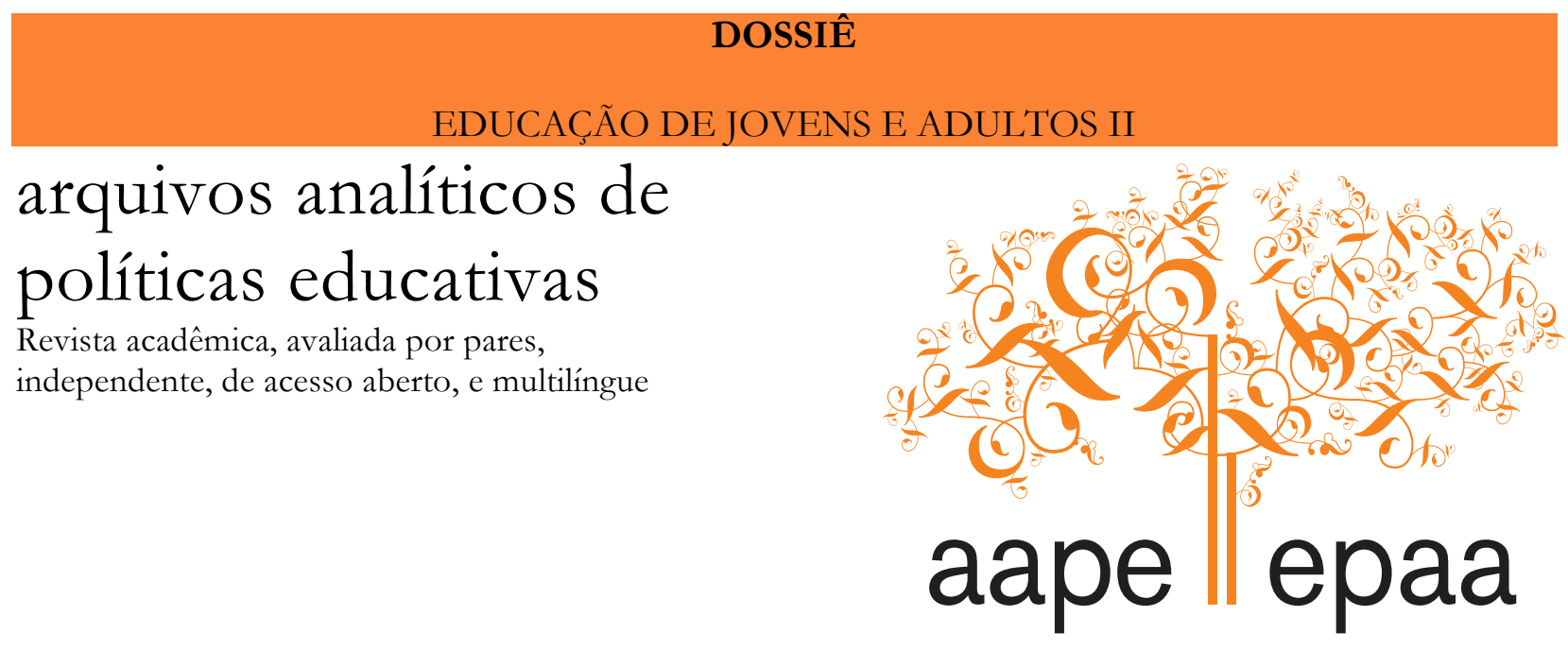

Volume 22 Número 60

30 de Junho de 2014

ISSN 1068-2341

\title{
Aproximações entre ofertas de educação de jovens e adultos com foco na juventude: perfis e espaços
}

\author{
Eliane Ribeiro \\ Universidade Federal do Estado do Rio de Janeiro \\ Luiz Carlos de Souza \\ Pontifícia Universidade Católica do Rio de Janeiro \\ \& \\ Maria Virginia de Freitas \\ Ação Educativa - SP \\ Brasil
}

Citação: Ribeiro, E; Souza; L. C.; Freitas, M. V. (2014). Aproximações entre ofertas de educação de jovens e adultos com foco na juventude: perfis e espaços. Arquivos Analíticos de Políticas Educativas, 22 (60). http://dx.doi.org/10.14507/epaa.v22n60.2014. Dossiê Educação de Jovens e Adultos II. Editoras convidadas: Sandra Regina Sales \& Jane Paiva

Resumo: Este trabalho se insere nos debates sobre as atuais políticas públicas de educação para a juventude no Brasil. Neste contexto, realiza comparações entre a oferta do Programa Nacional de Inclusão de Jovens - ProJovem Urbano (PJU) e a da Educação de Jovens e Adultos (EJA). O objetivo central é buscar indícios dos possíveis efeitos sociais do PJU sobre as condições de oferta educacional para a juventude, em comparação às condições oferecidas pela EJA ao seu público jovem. $\mathrm{Na}$ análise, efetuamos procedimentos de estatística descritiva básica, comparando perfis de alunos, professores e escolas a partir de dados oriundos do sistema de monitoramento e avaliação do PJU e também do Censo Escolar - INEP. As comparações explicitam semelhanças e diferenças entre os dois 
cenários. Estatisticamente, as comparações mostram que em alguns dos aspectos analisados a oferta do PJU é melhor que a da EJA. Por outro lado, evidenciam também aspectos em que a EJA oferece melhores condições que o PJU. Estas diferenciações influenciam qualitativamente a oferta educacional para a juventude e apontam para a necessidade de se aprofundar a compreensão sobre suas causas, bem como sobre as estratégias possíveis para seu enfrentamento.

Palavras-chave: Juventude; Políticas públicas; Avaliação de programas.

Comparisons between education offerings for youth and adults with a focus on youth: profiles and spaces

Abstract: This paper fits in debates on public policies for young people education in Brazil. In this context, performs comparisons between the offer of the Programa Nacional de Inclusão de Jovens - ProJovem Urbano (PJU) and the Education of young people and Adults (EJA). Our goal is to find evidences of PJU's possible social effects over educational provision for young people, compared to the conditions offered by the EJA to its young audience. In the analysis, were developed basic descriptive statistics procedures, comparing profiles of students, teachers and schools, using data from the monitoring system of the PJU and also those from Censo Escolar - INEP database. Comparisons explain similarities and differences between the two scenarios. Statistically, the comparisons show that in some of the aspects analyzed PJU's offer is better than the EJA. On the other hand, also show ways in which the EJA offers better conditions than the PJU. These differences influence qualitatively the educational provision for young people and point to the need of a deeper approach to the understanding of its causes, as well as possible strategies for its treatment.

Keywords: Youth; Public Policies; Program Evaluation.

Comparaciones entre las ofertas de educación para jóvenes y adultos con un enfoque en la juventud: perfiles y espacios

Resumen: Este trabajo se encuadra en los debates sobre políticas públicas para la educación de los jóvenes en Brasil. En este contexto, realiza comparaciones entre la oferta del Programa Nacional de Inclusión de los Jóvenes - ProJovem Urbano (PJU) y la Educación de Jóvenes y Adultos (EJA). El objetivo central es la búsqueda de evidencia de los posibles efectos sociales del PJU en la oferta educativa para los jóvenes, en comparación con las condiciones ofrecidas por la EJA a su joven audiencia. Para el análisis, llevamos a cabo estudios estadísticos descriptivos básicos, comparando los perfiles de los estudiantes, profesores y escuelas con dados derivados de lo sistema de seguimiento y evaluación del PJU y el Censo Escolar - INEP. Comparaciones explican las similitudes y diferencias entre los dos escenarios. Estadísticamente, las comparaciones muestran que en algunos de los aspectos que se analizaron la oferta de PJU es mejor que la EJA. Sin embargo, también se mostrará la manera en la que la EJA ofrece mejores condiciones que PJU. Estas diferencias influyen cualitativamente en la prestación de la educación a los jóvenes y apuntan a la necesidad de profundizar el conocimiento de sus causas, así como las posibles estrategias de afrontamiento.

Palabras-clave: Juventud; Política Pública; Evaluación del Programa. 


\section{Introdução}

À imagem da história, a investigação comparada não deve centrar-se sobre os 'factos' ou as 'realidades', mais sobre os problemas. Os 'factos' - acontecimentos, países, sistemas, etc. são, por definição, incomparáveis. É possível iluminar as 'especificidades' e as 'semelhanças', mas não se pode ir mais longe. Somente os 'problemas' podem ser erigidos em matériaprima [o que permitirá produzir] novas zonas de olhar que se projectem num espaço que não é delimitado por fronteiras físicas, mais sim por fronteiras de sentido (Nóvoa, 2005, p. 49).

Aproximar políticas e programas que transitam por uma mesma época, por mesmos espaços e pelo mesmo campo do conhecimento, é, sem dúvida, um grande desafio para a pesquisa educacional. Como destaca Arretche (2003), esse tipo de estudo pode acontecer a partir do que a autora chama de "Estado em ação", que seriam programas governamentais, muitas vezes caracterizados como emergenciais, em que o olhar sobre seus mecanismos de operação e prováveis impactos sobre a ordem social e econômica torna-se central na leitura das políticas públicas. Para tanto, é necessária a mobilização de um conjunto de dados diversos, na perspectiva de revelar, entender e, especialmente, criticar propositivamente bases, fundamentos e argumentos que os sustentam, buscando identificar semelhanças e diferenças no conjunto de sujeitos, instituições e práticas que conformam a ação desenvolvida. A aproximação, nesse caso, deve ter a finalidade de desvelar o universal nos processos singulares e o singular no universal, considerando, sobretudo, que nada pode existir independentemente da totalidade a que pertence e que lhe dá sentido. Para tanto, é importante considerar que tanto o universal, quanto o particular, se transformam sucessivamente, já que estão inseridos em realidades sociais dinâmicas e complexas. Conforme lembra Zemelmam (2003):

Los procesos asociados a políticas concretas deben ser analizados en sus determinaciones y sobredeterminaciones; esto es en su articulación dinámica y no como simples situaciones producidas por una lógica de factores encadenados, ninguno de los cuales aparece afectado por exigencias de especificidades históricas. De ahí que el desafío de la comparación la entendemos que reside en la capacidad de comparar la articulación que hace a un fenómeno, en cuanto a aquella que configura la especificidad de este. En efecto, lo que se compara es una situación de historicidad: esto es, como producto de procesos que han convergido en ella; pero también la historicidad entendida como latencia de posibilidades. (Entrevista com Hugo Zemelmam, realizada por Krawczyk, N. R. E Moraes, R. C. C. 2003).

No caso específico da educação de jovens e adultos, em pesquisa publicada em 2006, Spósito, Silva e Souza identificaram 796 programas/projetos voltados para jovens, desenvolvidos em 74 municípios de regiões metropolitanas. Os autores explicitam a importância da esfera municipal de gestão não somente na formulação/execução das ações destinadas à juventude, mas também ao próprio estabelecimento do entendimento do termo "juventude" e, ao mesmo tempo, como este entendimento acaba por fundamentar os modelos e práticas destas ações.

Baseando-se em dados desta mesma pesquisa, Haddad (2007) ressalta a crescente atuação das gestões municipais com a implantação de programas de EJA, quando comparada a outras esferas do poder público e da sociedade civil. Para ele, no âmbito das recentes reformas educacionais brasileiras, "tanto por imposição legal quanto por pressão da sociedade, os municípios têm tomado em suas mãos a responsabilidade política por atender essa população, oferecendo principalmente os anos iniciais da escolarização básica.” (Haddad, 2007, p. 199). Corroborando esta afirmação, o autor demonstra que as equipes técnicas das próprias gestões municipais aparecem como as principais 
responsáveis pela execução dos 125 programas/projetos por ele analisados, conforme se pode observar na tabela 1 , a seguir.

Tabela 1

Participação na elaboração do programa/projeto

\begin{tabular}{|l|l|l|}
\hline Instâncias & Número & Porcentagem \\
\hline Equipes técnicas & 108 & 61 \\
Sociedade civil & 19 & 11 \\
Governos de estado & 8 & 4 \\
Governo federal & 8 & 4 \\
Universidades & 10 & 6 \\
Outros & 25 & 14 \\
\hline Total & 178 & 100 \\
Obs: Questão de múltipla escola. Número base: 125 \\
programas/projetos
\end{tabular}

Fonte: Haddad (2007, p. 202)

É interessante notar que as articulações dos municípios com os governos federal e estaduais aparecem com pouca frequência. No entanto, é justamente esta uma das características fundamentais do PJU, ou seja, seu estabelecimento em regime de colaboração com estados e municípios. É intrigante pensar em como municípios acostumados a formular, gerir, financiar, executar e avaliar seus próprios programas e políticas de juventude encaram um programa formulado, financiado, em grande parte gerido e avaliado de forma centralizada pelo Governo Federal, cabendo-lhes, ainda que com relativa autonomia, atuar como executores de pressupostos previamente estabelecidos. Mais que isto, é intrigante imaginar como os municípios interpretam a política e reagem à necessidade de cumprimento de pressupostos aplicados em âmbito nacional, tendo em vista suas especificidades políticas, econômicas e culturais locais. A este respeito, valem as colocações de Haddad (2007)

Quando os programas são de "autoria" de outras esferas de governo, o poder local assume a tarefa de mero executor. A esse respeito, cabe investigar quais os resultados alcançados por programas/projetos concebidos, por exemplo, em âmbito federal, com o objetivo de serem implementados indistintamente em municípios com realidades diferenciadas. (Haddad, 2007 p. 201)

Os dados apresentados pelas pesquisas aqui referenciadas fornecem elementos para a hipótese de que existem fatores importantes a serem considerados quando políticas e programas educacionais são executados em parceria por diferentes esferas do poder público. Para os propósitos da presente discussão, cabe reiterar a importância de se analisar como a descentralização da execução de políticas e programas educacionais, através das parcerias que vêm sendo estabelecidas entre a União, os estados e municípios tem caracterizado a oferta da educação de jovens e adultos.

Em se tratando da complexidade resultante da multiplicidade de níveis de governo envolvidos, de atores e de localidades com suas respectivas especificidades, interesses, posicionamentos, trajetórias históricas, limitações econômicas etc., o PJU se mostra um cenário rico e propício para uma análise destas questões. Ao mesmo tempo, torna-se um enorme desafio prever que características programas como este podem assumir em função do local onde são postos em execução, bem como os efeitos educacionais e sociais que podem vir a produzir sobre os indivíduos envolvidos e sobre a oferta educacional pelos governos locais. É, portanto, tarefa relevante 
compreender suas contribuições, seus possíveis entraves, suas dificuldades de execução quando se busca contribuir de forma significativa não só para a ampliação do acesso à educação básica pública, mas principalmente por uma educação pública abrangente que conserve níveis satisfatórios de qualidade.

O objetivo das comparações que aqui efetuamos entre o PJU e a EJA, através dos dados do Censo Escolar do INEP, é justamente o de buscar alguns indícios dos possíveis efeitos sociais deste programa federal sobre os municípios. Por outro lado, é inegável que também existem efeitos dos municípios sobre a execução de programas deste tipo e para maior compreensão destes efeitos outras pesquisas se fazem necessárias.

Com essas preocupações, o estudo aqui apresentado, busca resgatar algumas discussões substanciais para se pensar políticas públicas para a educação de jovens e adultos na dimensão do recorte por identidade. No caso em questão, o foco está na juventude, por meio do ProJovem urbano - Programa Nacional de Inclusão de Jovens ${ }^{1}$. Cabe perguntar: a criação de um programa de escolarização para a conclusão do Ensino Fundamental, voltado especificamente para jovens de 18 a 29 anos, se sobrepõe a oferta tradicional de EJA desenvolvida nos âmbitos municipais e estaduais? Onde se aproxima e onde se distancia o perfil dos jovens participantes das distintas ofertas de EJA? Que escolas e que equipamentos estão disponibilizados para a EJA? Que professores atuam nessas ofertas?

\section{Novas agendas para a juventude brasileira}

O início do século XXI, caracterizado pelo ritmo intenso de mudanças econômicas, tecnológicas e culturais que seguem a globalização, demanda um olhar particular para a juventude como segmento social mais afetado pelas modificações em andamento. No Brasil, pode-se observar uma crescente valorização da compreensão dos jovens como sujeitos de direitos, com intenso registro no debate sobre direitos humanos. A incorporação da expressão ao vocabulário que se inscreve no campo da juventude reflete, por um lado, o fortalecimento de uma identidade social - juventude -, até então difusa e pouco estabelecida, e, por outro, convoca, necessariamente, à participação dos Estados Nacionais na construção de políticas públicas para esse conjunto de atores sociais que ganha expressiva visibilidade na esfera pública.

Para Novaes (2007, p. 3), a juventude é como um espelho retrovisor da sociedade. Mais do que comparar gerações é necessário comparar as sociedades que vivem os jovens de diferentes gerações. Ou seja, em cada tempo e lugar, fatores históricos, estruturais e conjunturais determinam as vulnerabilidades e as potencialidades das juventudes. Os jovens do século XXI, que vivem em um mundo que conjuga um acelerado processo de globalização e múltiplas desigualdades sociais, compartilham uma experiência geracional historicamente inédita. Para além das evidentes distâncias sociais que os separam, os jovens de hoje vivem em um momento no qual a tensão local-global se manifesta no mundo de maneira contundente. Nunca houve tanta integração globalizada e ao mesmo tempo, nunca foram tão agudos os processos de exclusão e profundos os sentimentos de desconexão. É verdade que estes aspectos têm consequências na sociedade como um todo, para todas as faixas etárias. Mas suas repercussões se agigantam sobre a juventude. Afinal as profundas mutações no mercado de trabalho atingem de maneira particular os jovens. É nesta fase da vida que

${ }^{1}$ O PJU teve origem na Secretaria Nacional de Juventude, vinculado a Secretaria Geral da Presidência da República, sendo transferido em 2012 para a Secretaria de Educação Continuada, Alfabetização, Diversidade e Inclusão - SECADI , do Ministério da Educação, criando, inclusive, uma Diretoria de Políticas Educacionais para Juventude. 
se busca condições para a emancipação. , as relações entre juventude e sociedade se fazem como em uma espécie de jogo de espelhos: ora apenas retrovisor, ora retrovisor e agigantador. Neste peculiar jogo dialético se produzem marcas geracionais, sensibilidades e disposições simbólicas comuns aos jovens que vivem em um mesmo tempo social.

Considerando que as políticas são construídas a partir de um olhar sobre esses atores sociais, condição e situação de vida e, por conseguinte, do conjunto de dificuldades vivenciadas, o deslocamento de um olhar sobre juventude que a qualifica como "problema", para "visões e lógicas mais compreensivas e precisas do complexo mundo juvenil" (León, 2008, p. 32), parece estar repercutindo positivamente em estados e municípios brasileiros, especialmente nos últimos dez anos, como pode ser observado na construção de uma relativa institucionalidade, especialmente no que se refere à implementação de programas e projetos, mesmo que, na maioria das vezes, construídos com a preocupação de dar respostas imediatas a supostos problemas que adquirem uma visibilidade pública (León, 2008, p. 33).

Para tanto, foi necessária a construção de uma visibilidade positiva desse grupo, já que como alertou Abramo (1997) parece estar presente, na maior parte da abordagem relativa aos jovens, tanto no plano da sua tematização como das ações a eles dirigidas, uma grande dificuldade de considerar efetivamente os jovens como sujeitos, mesmo quando é essa a intenção, salvo raras exceções; uma dificuldade de ir além da sua consideração como "problema social" e de incorporá-los como capazes de formular questões significativas, de propor ações relevantes, de sustentar uma relação dialógica com outros atores, de contribuir para a solução dos problemas sociais, além de simplesmente sofrêlos ou ignorá-los.

Assim, desde a década de 2000, o Brasil vem construindo uma nova agenda para a juventude, centrada na especificidade dos jovens, na pluralidade da condição juvenil, nos espaços para a participação e influência direta dos jovens, na associação de aspectos de proteção com os de promoção de oportunidades e desenvolvimento e na condição do jovem como sujeito de direitos. Em um fenômeno sem precedentes na sociedade brasileira, desvela-se um conjunto complexo e distinto de novos atores sociais, que soma, com muita força, às clássicas demandas por maior inclusão e bem-estar social, as demandas por reconhecimento da sua diversidade e da sua identidade.

Nesse contexto, em 2005 o governo federal criou um arcabouço institucional específico para políticas de juventude: a Secretaria Nacional de Juventude (SNJ), reconhecidas como de 15 a 29 anos, com a missão de articular as políticas desenvolvidas pelos diferentes ministérios, o Conselho Nacional de Juventude (CNJ), órgão de articulação entre o governo e a sociedade civil; e o ProJovem - Programa Nacional de Inclusão de Jovens, para jovens que não concluíram o Ensino Fundamental, no âmbito da educação de jovens e adultos. Cabe ressaltar, que dos 49,8 milhões de jovens brasileiros - ou seja, 26,5\% da população total no país (Brasil/IBGE/PNAD, 2008) - cerca de 25 milhões $(50 \%)$ têm experimentado, de forma mais radical, os efeitos dessas mudanças, gerando ou reforçando situações de distinções e desigualdades na "corrida de obstáculos" em que se constitui a vida de cada um deles e, muito particularmente, seus percursos escolares.

Outros aspectos que merecem atenção são o sentido e o significado desse investimento escolar na relação com conquistas e projeções de futuro, o que, sem dúvida, direta e indiretamente está relacionado com o papel do Estado e com a construção de políticas públicas. É fato, contudo, que a pressão política de uma gama de grupos diversificados, institucionais ou não, juvenis ou não, acaba por incidir nas agendas locais e nacionais, fomentando ações de juventude. Com isso, percebese que as políticas sociais que constituem, hoje, parte integrante das modernas políticas de Estado - e que visam a melhoria de vida dos cidadãos - tendem a estar associadas a uma visão integral desses jovens e ancoradas no reconhecimento dos mesmos como "sujeitos de direitos". Nesse contexto, a educação da juventude ganha relevância e destaque no debate público nacional, conquistando programas específicos para o segmento. É o caso do ProJovem, primeira política nacional, de 
educação de jovens e adultos, voltada, exclusivamente, para jovens entre 18 e 24 anos, que busca articular educação, trabalho e a cidadania. Não é a toa que, as principais demandas dos jovens, proclamada na II Conferência Nacional de Juventude, realizada em Brasília/DF, em dezembro de 2011, podem ser traduzidas em: ampliar o acesso e a permanência na escola pública de qualidade; acabar com o analfabetismo juvenil; preparar para o mundo do trabalho; gerar trabalho e renda; promover vida saudável; democratizar o acesso ao esporte, ao lazer, à cultura e à tecnologia da informação; promover os direitos humanos e as políticas afirmativas; estimular a cidadania e a participação social; e melhorar a qualidade de vida dos jovens no meio rural e nas comunidades tradicionais. $\mathrm{Na}$ base deste debate encontra-e, como questão central, a garantia dos direitos sociais.

Com essas preocupações, o estudo aqui apresentado integra a pesquisa O Projovem Urbano: seus impactos nas políticas de EJA e Juventude e na trajetória educacional dos jovens e foi realizado por meio da parceria entre a ONG Ação Educativa e o Grupo de Pesquisa Políticas em Educação, vinculado ao Programa de Pós-graduação em Educação da Universidade Federal do Estado do Rio de Janeiro UNRIO, com financiamento do Instituo Nacional de Estudos e Pesquisas em Educação - INEP, do Ministério da Educação. Nessa etapa, buscou-se aproximar elementos disponíveis nas bases de dados do Censo Escolar de educação de jovens e adultos do INEP e do banco de dados do PJU, da Secretaria Nacional de Juventude, com o objetivo de identificar o que há de comum e específico nessas ações educativas, em especial nos alunos jovens que frequentam as duas ações, considerando, sobretudo, que apesar de ambas fazerem parte de uma mesma modalidade educativa (educação de jovens e adultos), apresentam foco de público, modelos pedagógicos e gestão diferenciados. Contudo, o marco de diferença está em seu direcionamento ao segmento juvenil, recorte estabelecido pelo PJU, com a finalidade de proporcionar formação integral ao jovem, por meio da associação entre elevação da escolaridade, tendo em vista a conclusão do Ensino Fundamental; qualificação com certificação de formação inicial; e desenvolvimento de ações comunitárias de interesse público.

A aposta na construção de um programa específico para a juventude, no âmbito da EJA, faz parte do fomento de uma política nacional articulada com programas e ações voltados para o desenvolvimento integral do jovem brasileiro, na direção da institucionalização de políticas públicas de juventude e na visibilidade política de atores tão importantes em nossa sociedade. Neste sentido, torna-se fundamental cotejar as ações e entender o contexto em que se inserem.

\section{Procedimentos metodológicos}

Para a realização da análise acerca da aproximação do PJU com a oferta da EJA nos municípios recorremos a um conjunto de dados do sistema de monitoramento e avaliação do PJU e também dados do Censo Escolar realizado pelo INEP. O PJU contou, desde seu início em $2008^{2}$ até o final de 2011, com um processo constante de recolha de informações, produzindo um rico e detalhado conjunto de dados sobre os alunos, escolas, docentes e gestores do programa. Por outro lado, o Censo Escolar do INEP colhe, anualmente, informações de toda a educação básica, oferecendo dados importantes sobre o cenário educacional brasileiro.

O Censo Escolar do INEP é marcadamente abrangente, já que se trata de uma coleta censitária de dados e também direcionada a todas as etapas e modalidades da educação básica. Outro

\footnotetext{
2 Note-se que o Projovem teve sua primeira edição iniciada em agosto de 2005, a qual foi finalizada em 2008. A partir do segundo semestre de 2008 deu-se início a uma nova versão do Programa, com diversas reformulações e então denominada Projovem Urbano - PJU. É especificamente sobre esta segunda versão que estamos tratando.
} 
fator importante a seu respeito advém do fato de que a forma como as variáveis foram construídas permite o diálogo com diversas outras bases de dados como o Censo Demográfico e a PNAD ${ }^{3}$, do Instituto Brasileiro de Geografia e Estatística (IBGE), e outras coletas como o $\mathrm{SAEB}^{4}$, do próprio INEP. Por outro lado o Censo Escolar apresenta alguns problemas de sistematização das informações disponibilizadas e certa limitação em relação ao caráter de tais informações. Após a análise dos questionários aplicados para coleta de informações sobre escolas, alunos, turmas e docentes foi possível perceber que a quase totalidade dos dados remete a aspectos infraestruturais ou administrativos. No caso dos dados sobre escolas e turmas esta característica não traz grandes implicações. Contudo, quando se trata de alunos e docentes é possível perceber uma carência de informações de cunho socioeconômico. Há apenas algumas informações de cunho sociodemográfico, como sexo, idade, local de nascimento e de endereço de residência. Há também informações sobre cor/raça, mas neste caso um problema foi identificado. Tanto para alunos quanto para docentes, em quase a metade dos casos, a resposta foi assinalada como "Não declarada". Esta ocorrência inviabilizou a utilização da informação ao mesmo tempo em que evidenciou a necessidade de revisão da coleta deste dado na dinâmica de aplicação dos instrumentos do Censo Escolar.

Para que pudéssemos lidar com dados colhidos pelo INEP no mesmo ano em que foram produzidos os dados do PJU, selecionamos o Censo Escolar de 2010. Após este alinhamento, considerando as especificidades das duas bases de dados (PJU e Censo Escolar), foram necessários vários procedimentos metodológicos prévios para que fosse possível realizar as comparações.

O primeiro recorte efetuado, que se aplicou tanto a alunos, quanto a docentes e escolas, diz respeito à relação de municípios analisados. Para que comparássemos o PJU com o restante da EJA tivemos que lidar apenas com os municípios em que foram colhidos os dados para o PJU. Cabe esclarecer que todos os bancos de dados do PJU utilizados foram compostos por dados amostrais, seja de alunos, de docentes ou de escolas. Ainda que a maioria dos municípios coincida nos três bancos, as amostras apresentam algumas diferenciações. Sendo assim, obtivemos dados de alunos de 74 municípios, dados de docentes de 45 municípios e dados de escolas de 67 municípios.

\footnotetext{
3 A Pesquisa Nacional por Amostra de Domicílios - PNAD, coleta dados anuais sobre características demográficas e socioeconômicas da população e, com periodicidade variável, informações sobre migração, fecundidade, nupcialidade, entre outras.

4 "O Sistema de Avaliação da Educação Básica - SAEB é composto por duas avaliações complementares. A primeira, denominada Aneb - Avaliação Nacional da Educação Básica, abrange de maneira amostral os estudantes das redes públicas e privadas do país, localizados na área rural e urbana e matriculados no $5^{\circ}$ e $9^{\circ}$ anos do Ensino Fundamental e também no $3^{\circ}$ ano do ensino médio. Nesses estratos, os resultados são apresentados para cada Unidade da Federação, Região e para o Brasil como um todo. A segunda, denominada Anresc - Avaliação Nacional do Rendimento Escolar, é aplicada censitariamente alunos de $5^{\circ}$ e $9^{\circ}$ anos do Ensino Fundamental público, nas redes estaduais, municipais e federais, de área rural e urbana, em escolas que tenham no mínimo 20 alunos matriculados na série avaliada. Nesse estrato, a prova recebe o nome de Prova Brasil e oferece resultados por escola, município, Unidade da Federação e país que também são utilizados no cálculo do Ideb. As avaliações que compõem o Saeb são realizadas a cada dois anos, quando são aplicadas provas de Língua Portuguesa e Matemática, além de questionários socioeconômicos aos alunos participantes e à comunidade escolar." (fonte: INEP - http://provabrasil.inep.gov.br/)
} 
Cruzamentos realizados em relação aos alunos

Projovem - SMA (Supervisão e avaliação do programa)
INEP - Censo Escolar

- Alunos-perfil

Sexo

Idade

Cruzamentos realizados em relação aos docentes

Projovem - SMA

INEP - Censo Escolar

- Docentes-perfil

- Sexo

Idade

Escolaridade

- Docentes - perfil

- Sexo

- Idade

Escolaridade

\title{
Cruzamentos realizados em relação às escolas
}

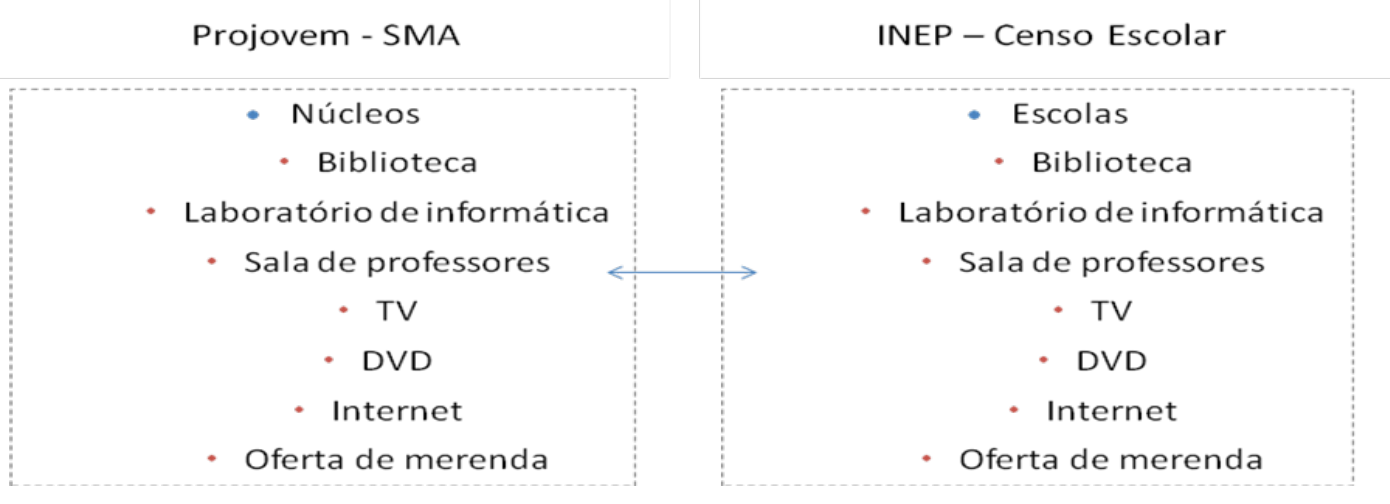

\section{PJU e EJA: aproximações plausíveis}

\begin{abstract}
Alunos
Em relação à variável sexo, percebe-se que o PJU conta com uma presença expressiva de mulheres. Chama a atenção, além da inversão de índices em relação à EJA, onde a presença de homens é maior, o fato de que as diferenças entre os percentuais são consideráveis. Assim, nota-se no gráfico 1 que o PJU conta com 32,6\% a mais de mulheres enquanto a EJA conta com 8,2\% a mais de homens. Dados colhidos junto aos estudantes do programa, apontam que 78,6\% das alunas têm filhos enquanto apenas $22,2 \%$ dos homens os têm. A presença de jovens do sexo feminino, com filhos, neste programa foi considerada tão marcante a ponto de sua coordenação nacional
\end{abstract}


instituir, a partir da entrada iniciada em 2012 um sistema de salas de acolbimento para que os alunos e as alunas que têm filhos entre zero e oito anos e precisam levá-los para a escola tenham um espaço onde deixá-los, no próprio local de estudo, enquanto frequentam as aulas.

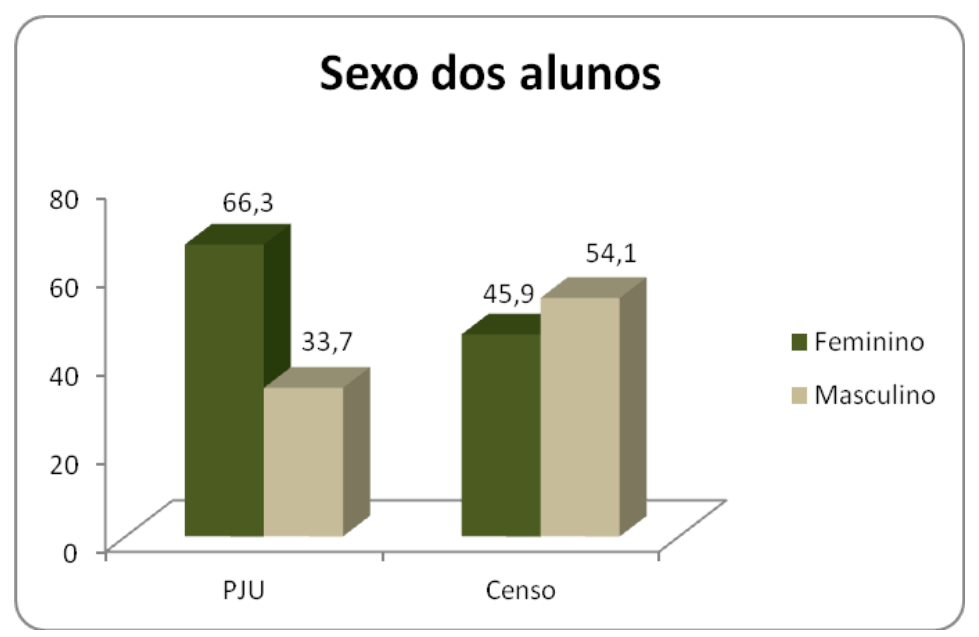

Gráfico 1.Proporção de alunos por sexo entre Projovem Urbano e EJA

Fonte: PJU e Censo Escolar-INEP

Mesmo quando agrupados por região do país, os dados revelam as mesmas tendências encontradas no âmbito Nacional. Nota-se, no entanto que na região norte há um equilíbrio em relação aos percentuais de homens e mulheres quando se trata da EJA, conforme se pode observar na tabela 2.

Tabela 2

Sexo dos alunos por região

\begin{tabular}{|c|c|c|c|c|c|c|c|}
\hline & \multicolumn{3}{|l|}{ EJA } & \multicolumn{3}{|l|}{ PJU } \\
\hline & & \multicolumn{3}{|l|}{ SEXO } & \multicolumn{3}{|l|}{ SEXO } \\
\hline & & Feminino & Masculino & Total & Feminino & Masculino & Total \\
\hline \multirow{5}{*}{ REGIÃO } & CENTRO-OESTE & $42,8 \%$ & $57,2 \%$ & $100 \%$ & $67,1 \%$ & $32,9 \%$ & $100 \%$ \\
\hline & NORDESTE & $46,0 \%$ & $54,0 \%$ & $100 \%$ & $68,2 \%$ & $31,8 \%$ & $100 \%$ \\
\hline & NORTE & $50,0 \%$ & $50,0 \%$ & $100 \%$ & $65,4 \%$ & $34,6 \%$ & $100 \%$ \\
\hline & SUDESTE & $43,7 \%$ & $56,3 \%$ & $100 \%$ & $66,5 \%$ & $33,5 \%$ & $100 \%$ \\
\hline & SUL & $42,8 \%$ & $57,2 \%$ & $100 \%$ & $61,3 \%$ & $38,7 \%$ & $100 \%$ \\
\hline \multicolumn{2}{|l|}{ Total } & $45,9 \%$ & $54,1 \%$ & $100 \%$ & $66,3 \%$ & $33,7 \%$ & $100 \%$ \\
\hline
\end{tabular}

Fonte: PJU e Censo Escolar-INEP

No tocante à faixa etária considerada como de juventude, ou seja, aquela entre 18 e 29 anos e que é o foco do PJU, nota-se, pelo gráfico 2, que ambos os cenários apresentam características semelhantes. A maioria dos alunos que integram a faixa etária de juventude têm entre 18 e 24 anos. No entanto, nota-se que na EJA há uma diferença ainda mais expressiva entre os percentuais encontrados, já que neste caso os jovens de 18 a 24 anos totalizam 72\% enquanto aqueles que possuem entre 25 e 30 anos representam $28 \%$. 


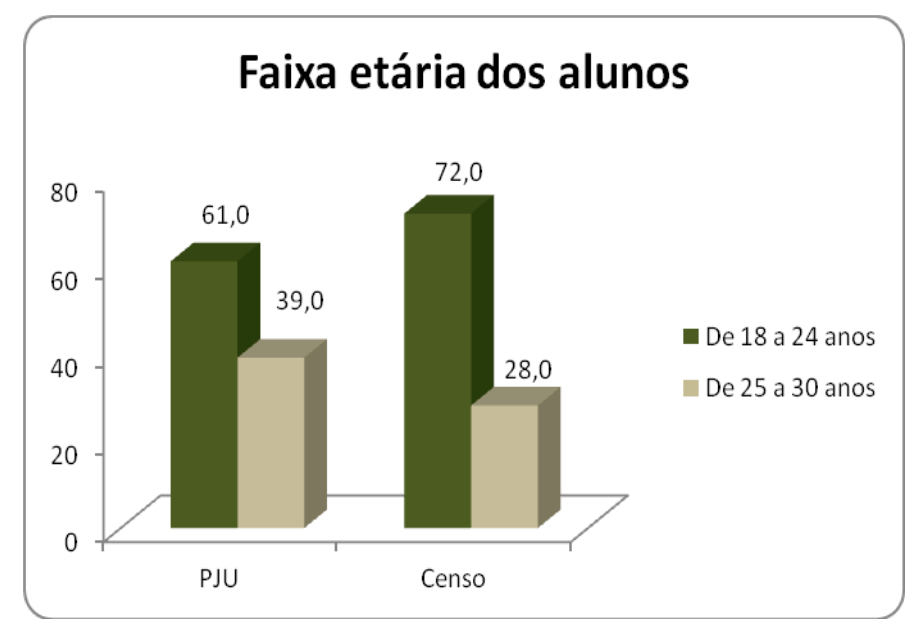

Gráfico 2. Faixas etárias dos alunos do PJU e da EJA Fonte: PJU e Censo Escolar-INEP

Quando se analisa os dados por região, conforme disposto na tabela 3, percebe-se que os percentuais mais expressivos de jovens entre 18 e 24 anos estão no sul do país, tanto para a EJA quanto para o PJU. Por outro lado, é na região Centro-oeste que os percentuais de jovens de 18 a 24 anos apresentam percentuais mais baixos e no caso do PJU eles quase se equiparam aos alunos de 25 a 30 anos ainda que se mantenham como a maioria.

Tabela 3

Faixa etária dos alunos por região

\begin{tabular}{|c|c|c|c|c|c|c|c|}
\hline & \multicolumn{3}{|l|}{ EJA } & \multicolumn{3}{|l|}{ PJU } \\
\hline & & \multicolumn{3}{|c|}{ FAIXA ETÁRIA (anos) } & \multicolumn{3}{|c|}{ FAIXA ETÁRIA (anos) } \\
\hline & & 18 a 24 & 25 a 30 & Total & 18 a 24 & 25 a 30 & Total \\
\hline \multirow{5}{*}{ REGIÃO } & CENTRO-OESTE & $67,9 \%$ & $32,1 \%$ & $100 \%$ & $50,8 \%$ & $49,2 \%$ & $100 \%$ \\
\hline & NORDESTE & $70,9 \%$ & $29,1 \%$ & $100 \%$ & $62,1 \%$ & $37,9 \%$ & $100 \%$ \\
\hline & NORTE & $71,4 \%$ & $28,6 \%$ & $100 \%$ & $63,6 \%$ & $36,4 \%$ & $100 \%$ \\
\hline & SUDESTE & $73,9 \%$ & $26,1 \%$ & $100 \%$ & $58,2 \%$ & $41,8 \%$ & $100 \%$ \\
\hline & SUL & $76,4 \%$ & $23,6 \%$ & $100 \%$ & $69,5 \%$ & $30,5 \%$ & $100 \%$ \\
\hline \multicolumn{2}{|l|}{ Total } & $72,0 \%$ & $28,0 \%$ & $100 \%$ & $61,0 \%$ & $39,0 \%$ & $100 \%$ \\
\hline
\end{tabular}

Fonte: PJU e Censo Escolar-INEP

\section{Docentes}

Os percentuais encontrados para o sexo dos docentes são semelhantes quando se compara o PJU ao restante da EJA. Conforme exposto no gráfico 3, as mulheres são a maioria nos dois cenários analisados $(67,3 \%$ e $72,9 \%$, respectivamente) sendo que na EJA a diferença entre o percentual de mulheres em relação ao de homens é ainda mais expressiva, de 45\%, enquanto no PJU esta diferença é de 34,6\%. 


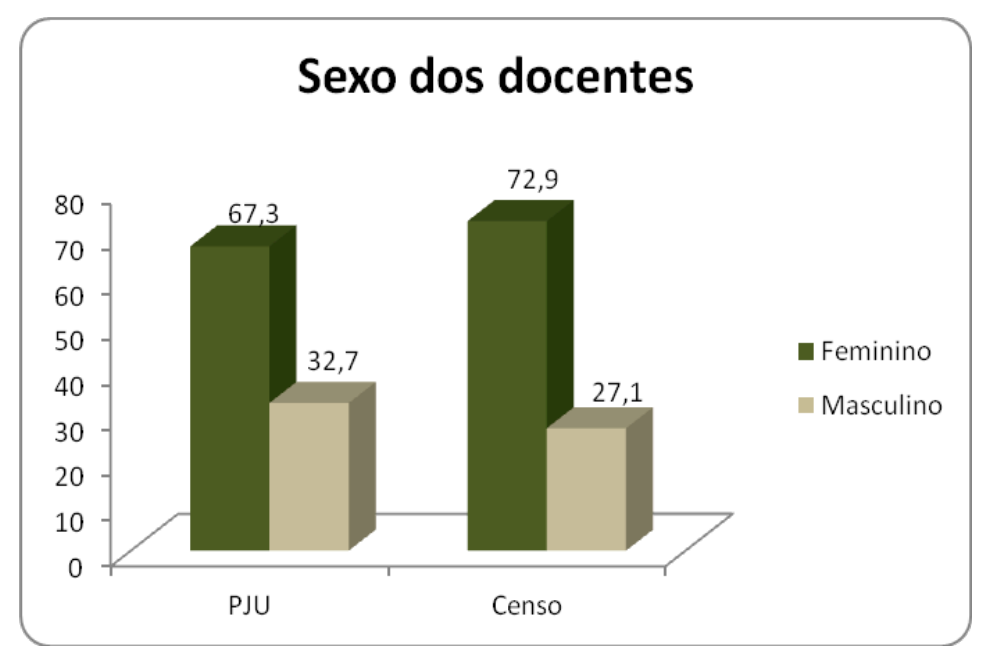

Gráfico 3. Proporções de docentes por sexo entre PJU e EJA Fonte: PJU e Censo Escolar-INEP

Como se pode observar na tabela 4, no recorte regional, pode notar-se que as tendências são mantidas. Contudo, há uma pequena diferenciação dos percentuais de mulheres em relação aos de homens quando se trata da região sul para a EJA e da região norte para o PJU, onde se encontram os menores percentuais de mulheres, ainda que estas se mantenham como a maioria dos docentes.

Tabela 4

Sexo dos docentes por região

\begin{tabular}{|c|c|c|c|c|c|c|c|}
\hline & \multicolumn{3}{|l|}{ EJA } & \multicolumn{3}{|l|}{ PJU } \\
\hline & & \multicolumn{2}{|l|}{ SEXO } & \multirow[b]{2}{*}{ Total } & \multicolumn{2}{|l|}{ SEXO } & \multirow[b]{2}{*}{ Total } \\
\hline & & Feminino & Masculino & & Feminino & Masculino & \\
\hline \multirow{5}{*}{ REGIÃO } & CENTRO-OESTE & $74,7 \%$ & $25,3 \%$ & $100 \%$ & $68,1 \%$ & $31,9 \%$ & $100 \%$ \\
\hline & NORDESTE & $72,9 \%$ & $27,1 \%$ & $100 \%$ & $68,0 \%$ & $32,0 \%$ & $100 \%$ \\
\hline & NORTE & $73,7 \%$ & $26,3 \%$ & $100 \%$ & $63,4 \%$ & $36,6 \%$ & $100 \%$ \\
\hline & SUDESTE & $71,8 \%$ & $28,2 \%$ & $100 \%$ & $68,8 \%$ & $31,2 \%$ & $100 \%$ \\
\hline & SUL & $66,1 \%$ & $33,9 \%$ & $100 \%$ & $65,0 \%$ & $35,0 \%$ & $100 \%$ \\
\hline Total & & $72,9 \%$ & $27,1 \%$ & $100 \%$ & $67,3 \%$ & $32,7 \%$ & $100 \%$ \\
\hline
\end{tabular}

Fonte: PJU e Censo Escolar-INEP

Com relação à faixa etária dos docentes é notória a diferenciação existente entre o PJU e a EJA nos municípios analisados. O gráfico 4 indica que ainda que nos dois cenários analisados a maioria dos docentes seja de adultos, o PJU parece ter atraído mais profissionais jovens, já que um conjunto bastante expressivo de respondentes informou ter 30 anos ou menos (40,4\%). Este número é de apenas 12,6\% no restante da EJA. 


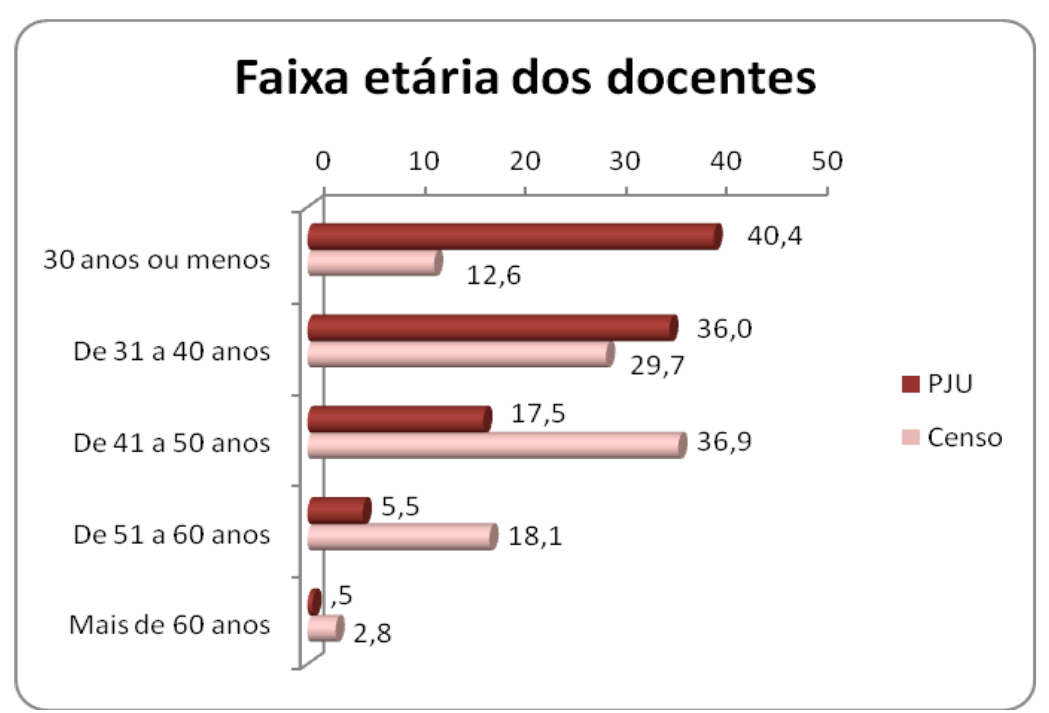

Gráfico 4. Proporções de docentes por faixa etária no PJU e na EJA Fonte: PJU e Censo Escolar-INEP

Quando se observa pelo recorte regional, pode-se notar na tabela 5 que, no PJU, os docentes com 30 anos ou menos têm os percentuais mais significativos no centro-oeste, no norte e no sudeste, enquanto nas regiões sul e nordeste a faixa etária de 31 a 40 anos é mais expressiva. Em relação à EJA, nota-se que apenas no sul os docentes têm percentual mais expressivo na faixa etária entre 31 e 40 anos. Nas demais regiões, os percentuais mais significativos são aqueles da faixa etária de 41 a 50 anos de idade.

Tabela 5

Faixa Etária dos docentes por região

\begin{tabular}{|c|c|c|c|c|c|c|c|c|c|c|}
\hline \multirow{3}{*}{ REGIÃO } & \multicolumn{10}{|c|}{ FAIXA ETÁRIA } \\
\hline & \multicolumn{2}{|c|}{30 ou menos } & \multicolumn{2}{|c|}{31 a 40 anos } & \multicolumn{2}{|c|}{41 a 50} & \multicolumn{2}{|c|}{51 a 60} & \multicolumn{2}{|c|}{ Mais de 60} \\
\hline & EJA & PJU & EJA & PJU & EJA & $\mathrm{PJU}$ & EJA & $\mathrm{PJU}$ & EJA & $\mathrm{PJU}$ \\
\hline CENTRO-OESTE & $15,2 \%$ & $47,9 \%$ & $30,3 \%$ & $33,0 \%$ & $35,5 \%$ & $17,0 \%$ & $17,0 \%$ & $2,1 \%$ & $2,0 \%$ & $0,0 \%$ \\
\hline NORDESTE & $10,3 \%$ & $36,6 \%$ & $27,8 \%$ & $39,4 \%$ & $39,0 \%$ & $18,7 \%$ & $19,8 \%$ & $4,6 \%$ & $3,1 \%$ & $0,7 \%$ \\
\hline NORTE & $12,7 \%$ & $39,4 \%$ & $33,2 \%$ & $36,6 \%$ & $34,6 \%$ & $18,2 \%$ & $17,7 \%$ & $5,5 \%$ & $1,9 \%$ & $0,3 \%$ \\
\hline SUDESTE & $14,8 \%$ & $44,1 \%$ & $30,0 \%$ & $32,5 \%$ & $35,8 \%$ & $15,5 \%$ & $16,2 \%$ & $7,3 \%$ & $3,2 \%$ & $0,6 \%$ \\
\hline SUL & $28,8 \%$ & $30,0 \%$ & $30,5 \%$ & $40,0 \%$ & $28,0 \%$ & $30,0 \%$ & $12,7 \%$ & $0,0 \%$ & $0,0 \%$ & $0,0 \%$ \\
\hline Total & $12,6 \%$ & $40,4 \%$ & $29,7 \%$ & $36,0 \%$ & $36,9 \%$ & $17,5 \%$ & $18,1 \%$ & $5,5 \%$ & $2,8 \%$ & $0,5 \%$ \\
\hline
\end{tabular}

Fonte: PJU e Censo Escolar-INEP

Outro dado interessante a este respeito surge quando se observa a experiência docente informada pelos respondentes. Por contar com um percentual maior de professores mais jovens, é de se esperar que os mesmos professores indicassem tempos menores de experiência profissional. Contudo, ainda que se leve em conta estes fatores, o PJU parece ter representado uma oportunidade de aquisição de experiência docente para profissionais recém-iniciados ou mesmo como uma primeira oportunidade de entrada no campo da docência. Conforme se pode observar na tabela 6 , a maioria dos respondentes possuía três anos ou menos de experiência (43,3\%) enquanto 19,2\% nunca havia lecionado. Infelizmente não foi possível comparar estas características do programa com o restante da EJA, pois o questionário do Censo Escolar não colhe estas informações. 
Tabela 6

Experiência docente por faixa etária dos respondentes - PJU

\begin{tabular}{|c|c|c|c|c|c|c|c|}
\hline \multirow[b]{2}{*}{ FAIXAS ETÁRIAS } & \multicolumn{6}{|c|}{ EXPERIENCIA DOCENTE } & \multirow[b]{2}{*}{ Total } \\
\hline & $\begin{array}{l}\text { Nunca } \\
\text { lecionou }\end{array}$ & $\begin{array}{l}\text { anos ou } \\
\text { menos }\end{array}$ & $\begin{array}{lrl}4 & \text { a } & 7 \\
\text { anos } & \\
\end{array}$ & \begin{tabular}{|lll}
8 & a & 11 \\
anos & \\
\end{tabular} & $\begin{array}{ll}12 \text { a } & 15 \\
\text { anos } & \end{array}$ & $\begin{array}{l}\text { Mais de } \\
15 \text { anos }\end{array}$ & \\
\hline 30 anos ou menos & $19,2 \%$ & $43,3 \%$ & $28,9 \%$ & $7,8 \%$ & $0,7 \%$ & $0,2 \%$ & $100,0 \%$ \\
\hline De 31 a 40 anos & $9,3 \%$ & $23,2 \%$ & $28,6 \%$ & $21,3 \%$ & $12,0 \%$ & $5,5 \%$ & $100,0 \%$ \\
\hline De 41 a 50 anos & $9,8 \%$ & $16,5 \%$ & $14,5 \%$ & $12,5 \%$ & $18,0 \%$ & $28,6 \%$ & $100,0 \%$ \\
\hline De 51 a 60 anos & $10,0 \%$ & $13,8 \%$ & $7,5 \%$ & $15,0 \%$ & $8,8 \%$ & $45,0 \%$ & $100,0 \%$ \\
\hline Mais de 60 anos & $0,0 \%$ & $12,5 \%$ & $12,5 \%$ & $0,0 \%$ & $12,5 \%$ & $62,5 \%$ & $100,0 \%$ \\
\hline
\end{tabular}

Fonte: SMA-PJU. Rotina 002 perfil de educadores, $\sigma^{\mathrm{a}}$ entrada.

Se por um lado os professores do PJU são relativamente jovens, com pouca ou mesmo nenhuma experiência profissional como docentes, por outro lado apresentam um nível de escolaridade ligeiramente maior que o restante dos professores da EJA. De acordo com os dados analisados e conforme se pode observar no gráfico 5 , há pequenas diferenças percentuais que indicam maior proporção de docentes do PJU com pós-graduação lato sensu e stricto senso. É importante mencionar que de acordo com as normas do programa, as coordenações municipais e estaduais só poderiam admitir profissionais com o ensino superior completo, à exceção daqueles que atuariam na qualificação profissional e que poderiam ter, no mínimo, um curso técnico de nível médio na área de atuação.

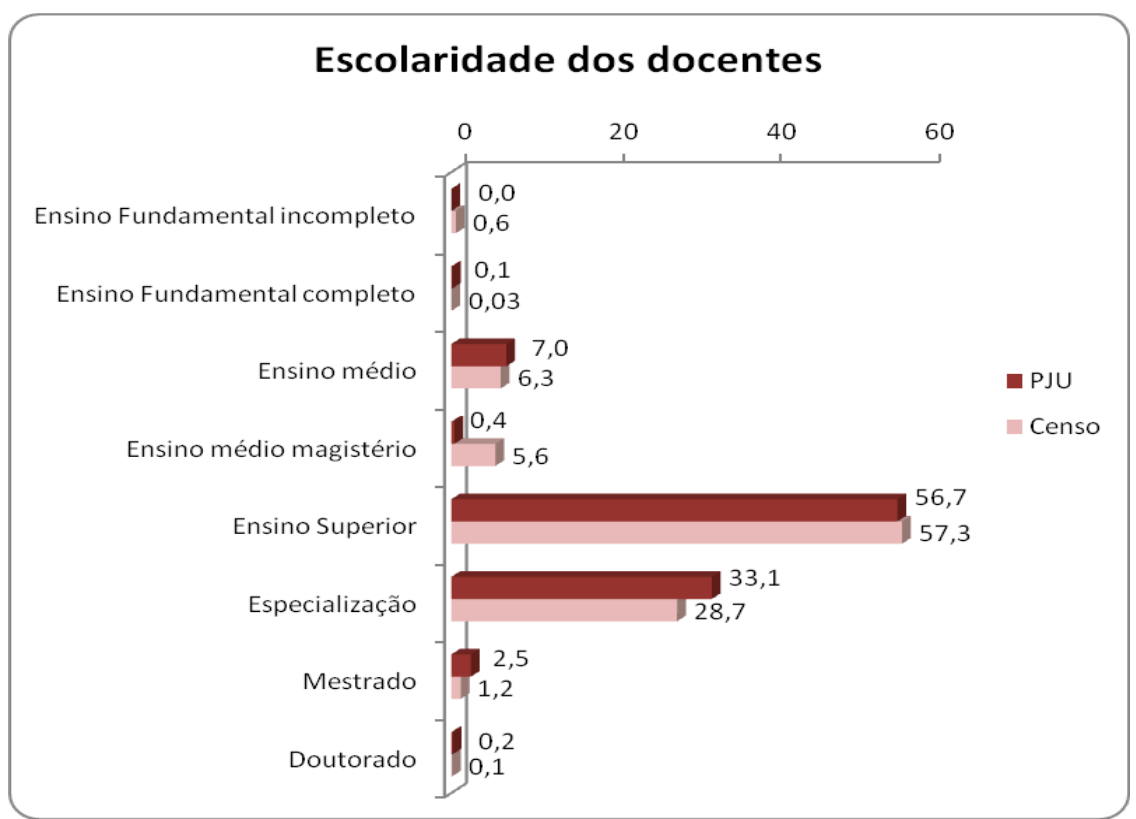

Gráfico 5. Níveis de escolaridade dos docentes do PJU e da EJA

Fonte: PJU e Censo Escolar-INEP

Quando considerados por região, percebe-se que há docentes atuando na EJA, na região nordeste, com o nível fundamental incompeto. Apesar disto não ocorrer no PJU, há docentes 
apenas com o nível fundamental completo atuando no programa, na região centro-oeste. Cnforme exposto na tabela 7, no PJU, a região sudeste é a que mais conta com docentes de nível superior (62\%), enquanto na EJA é a Região sul que apresenta maior percentual de docentes com este nível de formação $(70,3 \%)$. Os docentes com especialização no PJU atuam também, em sua maioria, no sul do país (65\%) ao passo que na EJA há uma distribuição mais equânime e pode-se perceber uma pequena diferença indicando maior número de docentes com especialização na região centro-oeste.

Tabela 7

Escolaridade dos docentes por região

\begin{tabular}{|c|c|c|c|c|c|c|}
\hline \multirow{2}{*}{$\begin{array}{l}\text { ESCOLARIDADE } \\
\text { DOS DOCENTES }\end{array}$} & \multirow{2}{*}{ MOD } & \multicolumn{5}{|l|}{ REGIÃO } \\
\hline & & CENTRO-OESTE & NORDESTE & NORTE & SUDESTE & SUL \\
\hline \multirow{2}{*}{$\begin{array}{l}\text { Ensino Fundamental } \\
\text { incompleto }\end{array}$} & EJA & $0,0 \%$ & $1,4 \%$ & $0,0 \%$ & $0,0 \%$ & $0,0 \%$ \\
\hline & $\mathrm{PJU}$ & $0,0 \%$ & $0,0 \%$ & $0,0 \%$ & $0,0 \%$ & $0,0 \%$ \\
\hline \multirow{2}{*}{$\begin{array}{l}\text { Ensino Fundamental } \\
\text { completo }\end{array}$} & EJA & $0,0 \%$ & $0,0 \%$ & $0,0 \%$ & $0,0 \%$ & $0,0 \%$ \\
\hline & PJU & $1,1 \%$ & $0,0 \%$ & $0,0 \%$ & $0,0 \%$ & $0,0 \%$ \\
\hline \multirow{2}{*}{ Ensino médio } & EJA & $2,1 \%$ & $9,3 \%$ & $6,0 \%$ & $3,7 \%$ & $0,0 \%$ \\
\hline & $\mathrm{PJU}$ & $1,1 \%$ & $6,3 \%$ & $14,4 \%$ & $4,5 \%$ & $10,0 \%$ \\
\hline \multirow{2}{*}{$\begin{array}{ll}\text { Ensino } & \text { médio } \\
\text { magistério }\end{array}$} & EJA & $1,3 \%$ & $6,8 \%$ & $6,2 \%$ & $5,0 \%$ & $0,0 \%$ \\
\hline & PJU & $1,1 \%$ & $0,2 \%$ & $0,3 \%$ & $0,6 \%$ & $0,0 \%$ \\
\hline \multirow{2}{*}{ Ensino Superior } & EJA & $63,0 \%$ & $50,9 \%$ & $66,0 \%$ & $59,2 \%$ & $70,3 \%$ \\
\hline & PJU & $52,1 \%$ & $52,9 \%$ & $58,2 \%$ & $62,0 \%$ & $25,0 \%$ \\
\hline \multirow{2}{*}{ Especialização } & EJA & $32,9 \%$ & $30,3 \%$ & $20,8 \%$ & $30,3 \%$ & $28,0 \%$ \\
\hline & PJU & $39,4 \%$ & $37,9 \%$ & $25,3 \%$ & $30,0 \%$ & $65,0 \%$ \\
\hline \multirow{2}{*}{ Mestrado } & EJA & $0,7 \%$ & $1,2 \%$ & $0,8 \%$ & $1,7 \%$ & $1,7 \%$ \\
\hline & PJU & $5,3 \%$ & $2,6 \%$ & $1,4 \%$ & $2,7 \%$ & $0,0 \%$ \\
\hline \multirow{2}{*}{ Doutorado } & EJA & $0,0 \%$ & $0,1 \%$ & $0,1 \%$ & $0,1 \%$ & $0,0 \%$ \\
\hline & PJU & $0,0 \%$ & $0,2 \%$ & $0,3 \%$ & $0,2 \%$ & $0,0 \%$ \\
\hline
\end{tabular}

Fonte: PJU e Censo Escolar-INEP

\section{Escolas}

A categoria "escola" foi a que mais apresentou possibilidades de cruzamentos entre o PJU e a EJA. Como já mencionado, quase todas as variáveis passíveis de cruzamentos referem-se a aspectos infraestruturais das escolas. Antes de iniciarmos este tópico cabem alguns esclarecimentos importantes. Como já é sabido, os instrumentos de coleta de dados elaborados para o PJU e para o Censo Escolar são bastante diferentes. Foram construídos com objetivos diferentes, contém perguntas e variáveis diferentes, foram aplicados a partir de metodologias diferentes e sistematizados pelos responsáveis também de maneiras diferentes. Já mencionamos que estas foram as principais razões que limitaram as possibilidades de cruzamentos entre as variáveis. Contudo, mesmo estas poucas variáveis passíveis de relacionamento ainda apresentam alguns pormenores que não podem ser deixados de lado, pois, de certa forma, eles acabam por exercer certa influência sobre os percentuais encontrados. As diferenças às quais nos remetemos aqui se referem à formulação das perguntas para a coleta dos dados.

Enquanto no Censo Escolar as perguntas acerca dos aspectos infraestruturais questionavam apenas se a escola possuía ou não certos itens ou características, nos instrumentos do PJU algumas perguntas foram construídas de forma a arguir ao mesmo tempo se o local de realização das atividades os possuía e se os disponibilizava ou não aos envolvidos no Programa. Assim, no caso das bibliotecas e das salas dos professores perguntava-se se alunos e docentes, respectivamente, tinham acesso a estes espaços. Nestes dois casos, são perguntas mais detalhadas e que não só averiguavam a 
existência de determinado item, mas principalmente seu uso. Já no caso dos laboratórios de informática, da Internet, dos aparelhos de TV, DVD/VHS e oferta de alimentação escolar as perguntas tinham o mesmo teor do Censo Escolar, ou seja, se a escola possuía ou não.

O primeiro aspecto apresentado é o da existência de bibliotecas nas escolas. Conforme disposto no gráfico 6, a maioria das escolas que oferecem a EJA possuem bibliotecas, totalizando $63,8 \%$ dos casos. Os dados relativos ao PJU, apresentados no gráfico a seguir indicam a existência do item num percentual ainda maior, de $88,1 \%$. Contudo, é possível identificar no banco de dados do programa que destes $88,1 \%$ há um total de 39,3\% de casos em que apesar da existência da biblioteca, os alunos não têm acesso à mesma. De acordo com informações existentes nos próprios registros de supervisão do PJU, em alguns casos a direção da escola mantém a biblioteca fechada, impedindo o acesso dos alunos do PJU. Em outros casos o acervo não é utilizado porque é constituído de obras direcionadas à educação infantil apenas. Sendo assim, a mera existência do espaço não significa necessariamente que o mesmo esteja disponível aos alunos. Esta informação permite melhor qualificar os dados, já que neste caso, a biblioteca é utilizada pela minoria (48,8\%).

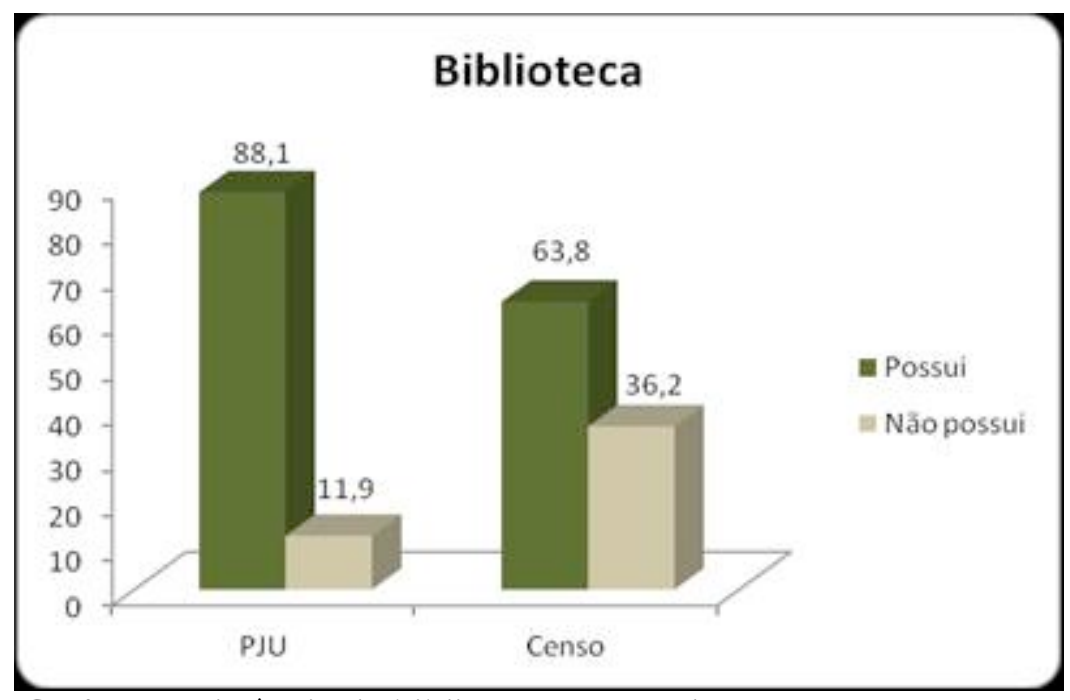

Gráfico 6. Existência de biblioteca em escolas com PJU e EJA

Fonte: PJU e Censo Escolar-INEP

No recorte regional percebe-se que tanto na EJA quanto no PJU, para todas as regiões do país mantém-se a tendência de que a maioria das escolas possuam bibliotecas. Contudo, a tabela 8 mostra que a região sul é a que mais possui bibliotecas nas escolas ( $94 \%$ na EJA e 100\% no PJU). Por outro lado, na EJA a região nordeste é a que menos possui bibliotecas nas escolas (58,8\%) enquanto no PJU o menor percentual encontrado é o da região norte $(74,5 \%)$.

Tabela 8

Existência de bibliotecas nas escolas com PJU e com EJA por região

\begin{tabular}{|l|l|l|l|l|l|}
\hline \multirow{2}{*}{ REGIÃO } & \multicolumn{3}{|l|}{ EJA } & PJU & \multirow{2}{*}{ Total } \\
\cline { 2 - 5 } & Possui & Não possui & Possui & Não possui & \\
\hline CENTRO-OESTE & $71,6 \%$ & $28,4 \%$ & $88,0 \%$ & $12,0 \%$ & $100 \%$ \\
\hline NORDESTE & $58,8 \%$ & $41,2 \%$ & $79,9 \%$ & $20,1 \%$ & $100 \%$ \\
\hline NORTE & $60,0 \%$ & $40,0 \%$ & $74,5 \%$ & $25,5 \%$ & $100 \%$ \\
\hline SUDESTE & $61,2 \%$ & $38,8 \%$ & $94,2 \%$ & $5,8 \%$ & $100 \%$ \\
\hline SUL & $94,1 \%$ & $5,9 \%$ & $100,0 \%$ &, $0 \%$ & $100 \%$ \\
\hline
\end{tabular}

Fonte: PJU e Censo Escolar-INEP 
Em relação aos laboratórios de informática, os dois cenários observados seguem as mesmas tendências. Assim, em ambos os casos a maioria das escolas possui laboratórios de informática. Identificamos um maior percentual de existência dos mesmos nas escolas do PJU onde 79,4\% os possuem e 20,6\% não os têm, como se pode ver pelo gráfico 7 .

É importante mencionar que o termo de cooperação estabelecido entre a União e os municípios que firmassem a parceria com o PJU estipulava como pré-requisito para escolha dos núcleos onde se realizariam as atividades do programa a existência prévia ou a disponibilização urgente de espaços onde pudessem ser montados laboratórios de informática. Como se pode perceber pelos dados apresentados, mesmo já em sua sexta entrada ${ }^{5}$ o programa ainda possuía um déficit de $20,6 \%$ deste item para seus alunos.

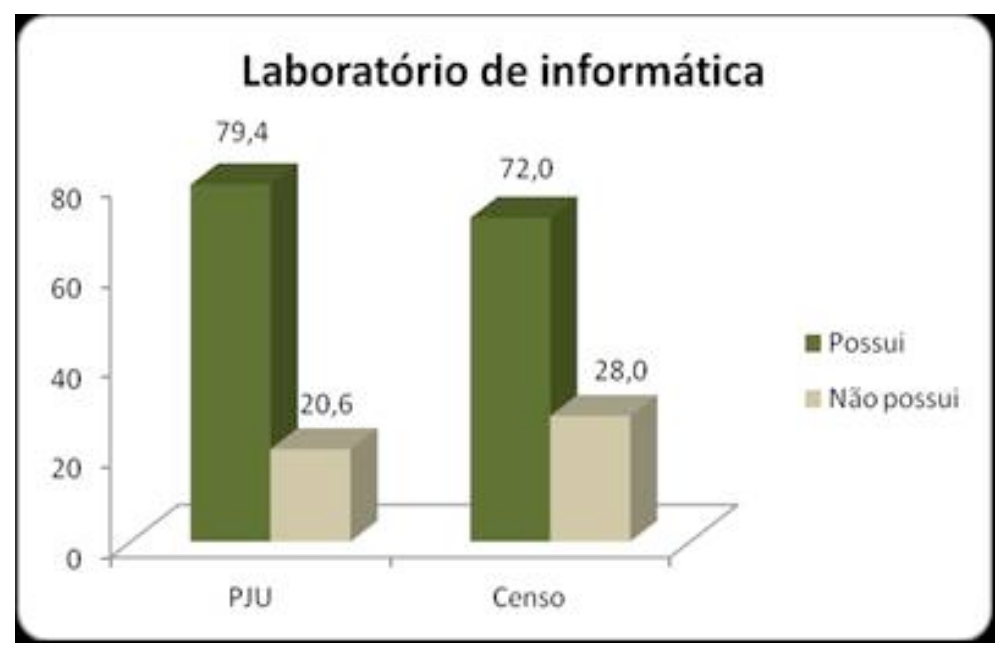

Gráfico 7. Existência de laboratório de informática nas escolas com PJU e com EJA

Fonte: PJU e Censo Escolar-INEP

No recorte regional nota-se, pela tabela 9, que as regiões sul e sudeste têm praticamente os mesmos níveis de oferta de laboratórios de informática no PJU (83,9\% e 83,7\% respectivamente). Por outro lado, as regiões nordeste e norte são as que menos ofertam os laboratórios tanto para a EJA quanto para o PJU, ainda que os tenham na maioria de suas escolas.

Tabela 9

Existência de laboratório de informática nas escolas por região

\begin{tabular}{|l|l|l|l|l|l|}
\hline \multirow{2}{*}{ REGIÃO } & \multicolumn{2}{|l|}{ EJA } & PJU & \multirow{2}{*}{ Total } \\
\cline { 2 - 5 } & Possui & Não possui & Possui & Não possui & \\
\hline CENTRO-OESTE & $79,6 \%$ & $20,4 \%$ & $80,0 \%$ & $20,0 \%$ & $100 \%$ \\
\hline NORDESTE & $69,0 \%$ & $31,0 \%$ & $67,2 \%$ & $32,8 \%$ & $100 \%$ \\
\hline NORTE & $61,8 \%$ & $38,2 \%$ & $79,1 \%$ & $20,9 \%$ & $100 \%$ \\
\hline SUDESTE & $73,8 \%$ & $26,2 \%$ & $83,9 \%$ & $16,1 \%$ & $100 \%$ \\
\hline SUL & $87,6 \%$ & $12,4 \%$ & $83,7 \%$ & $16,3 \%$ & $100 \%$ \\
\hline
\end{tabular}

Fonte: PJU e Censo Escolar-INEP

${ }^{5}$ Uma entrada do PJU corresponde a um mês e ano específicos de início das atividades do programa. Desde sua primeira entrada de alunos, em julho de 2008, o PJU, que tem uma duração de 18 meses, contou com outras cinco novas entradas, sendo que a sexta entrada corresponde à dos alunos que iniciaram as atividades em 24 de maio de 2010 e as concluíram em janeiro de 2012. 
No tocante à existência de Internet, percebe-se no gráfico 8 que, em ambos os casos, a maioria das escolas a possui ${ }^{6}$. Contudo, as escolas que oferecem a EJA se mostram ainda melhor equipadas que as que receberam o PJU. Assim como no caso dos laboratórios de informática, a disponibilização do acesso à Internet se configurava como uma responsabilidade das coordenações locais que aderissem ao programa. Contudo, percebe-se um déficit de oferta deste item em 25,7\% dos locais de funcionamento.

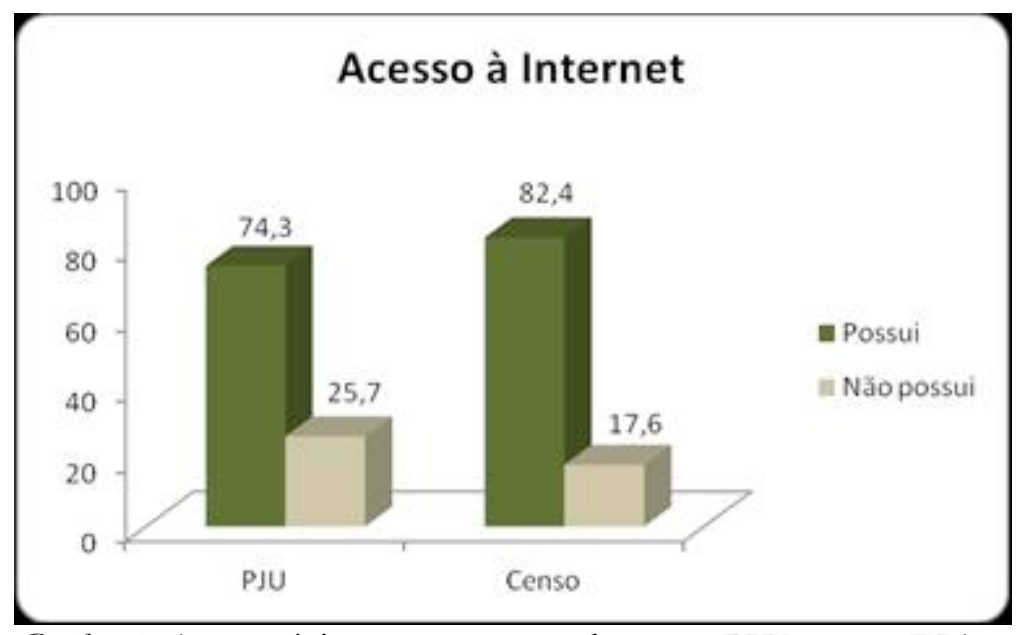

Gráfico 8. Acesso à internet nas escolas com PJU e com EJA

Fonte: PJU e Censo Escolar-INEP

No recorte por região, o que se percebe pela tabela 10 é que mais uma vez a região sul do país é a que apresenta os maiores percentuais de oferta de Internet nas escolas, tanto para a EJA $(96,9 \%)$ quanto para o PJU. Note-se que no caso do PJU a situação se diferencia um pouco, pois a região centro-oeste apresenta praticamente o mesmo percentual da região sul $(90,0 \%$ e 90,2\% respectivamente). Por outro lado, a região norte é a que menos oferece Internet nas escolas, ainda que as possua em sua maioria tanto para a EJA quanto para o PJU (65,1\% e 67,8\% respectivamente). Nas regiões sudeste e sul do país a EJA possui uma melhor oferta de Internet quando comparada ao PJU.

Tabela 10

Existência de Internet nas escolas por região

\begin{tabular}{|l|l|l|l|l|l|}
\hline \multirow{2}{*}{ REGIÃO } & \multicolumn{2}{|l|}{ EJA } & \multicolumn{2}{l|}{ PJU } & \multirow{2}{*}{ Total } \\
\cline { 2 - 5 } & Possui & Não possui & Possui & Não possui & \\
\hline CENTRO-OESTE & $90,9 \%$ & $9,1 \%$ & $90,0 \%$ & $10,0 \%$ & $100 \%$ \\
\hline NORDESTE & $75,2 \%$ & $24,8 \%$ & $76,7 \%$ & $23,3 \%$ & $100 \%$ \\
\hline NORTE & $65,1 \%$ & $34,9 \%$ & $67,8 \%$ & $32,2 \%$ & $100 \%$ \\
\hline SUDESTE & $91,3 \%$ & $8,7 \%$ & $72,1 \%$ & $27,9 \%$ & $100 \%$ \\
\hline SUL & $96,9 \%$ & $3,1 \%$ & $90,2 \%$ & $9,8 \%$ & $100 \%$ \\
\hline
\end{tabular}

Fonte: PJU e Censo Escolar-INEP

${ }^{6}$ Neste item, em relação aos dados do PJU, considerar os percentuais sobre 514 casos válidos ao invés dos 647 informados para todos os outros referentes às escolas, já que foram identificados 133 dados ausentes (uma redução de $20,6 \%$ em relação ao total original). 
Como pode ser observado no gráfico 9, a existência de aparelhos de TV nas escolas é também apontada como maioria tanto pelo Censo Escolar quanto pelo PJU. Neste caso, a oferta pelo PJU é 8,0\% menor que aquela apontada na EJA pelo Censo Escolar.

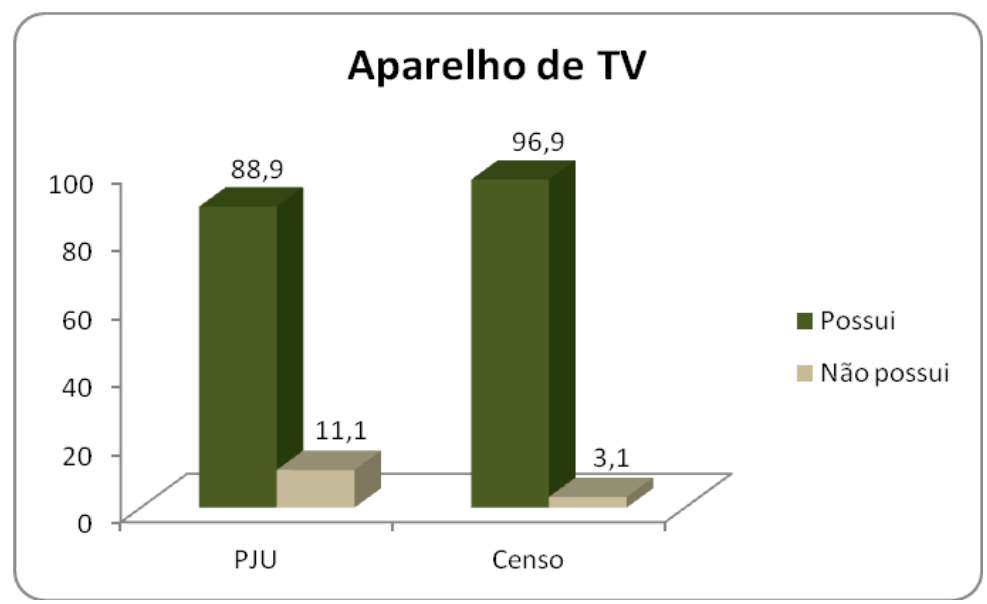

Gráfico 9. Existência de aparelho de TV nas escolas com PJU e EJA

Fonte: PJU e Censo Escolar-INEP

No recorte regional pode-se perceber na tabela 11 que em todas as regiões do país a EJA possui uma melhor oferta de aparelhos de TV, quando comparada com o PJU. Neste caso, vê-se que todos os percentuais da EJA ultrapassam $90 \%$ ao passo que no PJU há níveis pouco maiores que $80 \%$ no nordeste e no norte.

Tabela 11

Existência de TV nas escolas por região

\begin{tabular}{|l|l|l|l|l|l|}
\hline \multirow{2}{*}{ REGIÃO } & \multicolumn{2}{l|}{ EJA } & \multicolumn{2}{l|}{ PJU } & \multirow{2}{*}{ Total } \\
\cline { 2 - 5 } & Possui & Não possui & Possui & Não possui & \\
\hline CENTRO-OESTE & $98,6 \%$ & $1,4 \%$ & $92,0 \%$ & $8,0 \%$ & $100 \%$ \\
\hline NORDESTE & $95,1 \%$ & $4,9 \%$ & $80,6 \%$ & $19,4 \%$ & $100 \%$ \\
\hline NORTE & $95,1 \%$ & $4,9 \%$ & $81,8 \%$ & $18,2 \%$ & $100 \%$ \\
\hline SUDESTE & $98,5 \%$ & $1,5 \%$ & $93,6 \%$ & $6,4 \%$ & $100 \%$ \\
\hline SUL & $99,2 \%$ & $0,8 \%$ & $93,9 \%$ & $6,1 \%$ & $100 \%$ \\
\hline
\end{tabular}

Fonte: PJU e Censo Escolar-INEP

Praticamente as mesmas tendências são encontradas quando analisamos a existência de aparelhos de DVD ou de video cassete nas escolas. Como se pode perceber no gráfico 10, a maioria das instituições, em ambos os casos dispões destes itens. Contudo, o PJU apresenta uma oferta 9,4\% menor dos mesmos quando comparado com a EJA. 


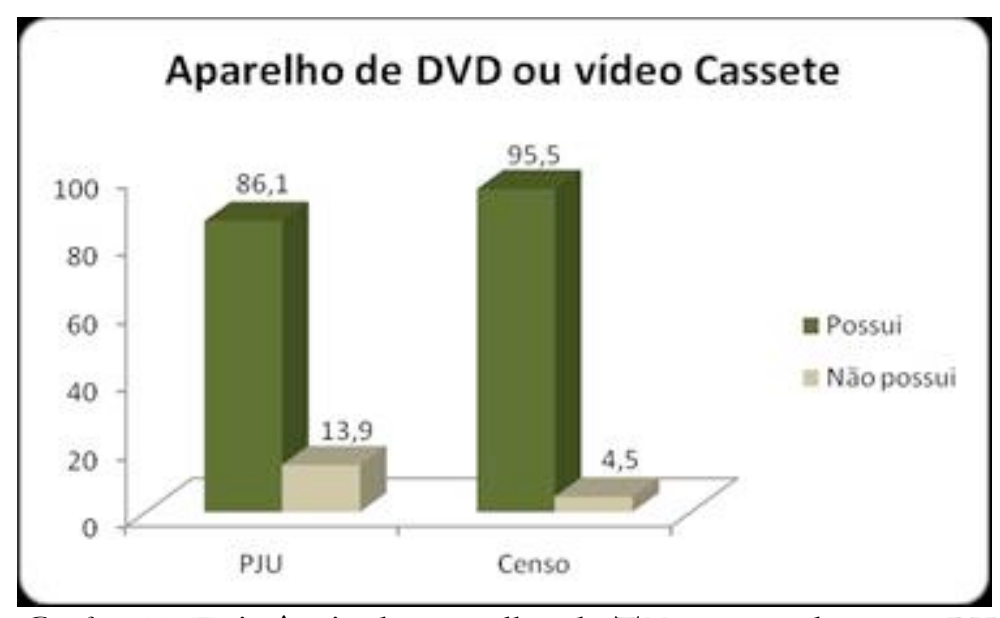

Gráfico 10. Existência de aparelho de TV nas escolas com PJU e EJA

Fonte: PJU e Censo Escolar-INEP

Assim como no caso da existência de TV nas escolas, o recorte regional nos mostra que em todas as regiões do país a EJA possui uma melhor oferta de equipamentos de DVD ou VHS, quando comparada com o PJU. Neste caso, na tabela 12, vê-se que todos os percentuais da EJA ultrapassam 90\% enquanto no PJU há níveis mais baixos de oferta de 78,4\% no nordeste e de 81,8\% no norte.

Tabela 12

Existência de aparelhos de DVD ou VHS nas escolas por região

\begin{tabular}{|l|l|l|l|l|l|}
\hline \multirow{2}{*}{ REGIÃO } & \multicolumn{2}{|l|}{ EJA } & \multicolumn{2}{l|}{ PJU } & \multirow{2}{*}{ Total } \\
\cline { 2 - 5 } & Possui & Não possui & Possui & Não possui & \\
\hline CENTRO-OESTE & $97,2 \%$ & $2,8 \%$ & $92,0 \%$ & $8,0 \%$ & $100 \%$ \\
\hline NORDESTE & $94,0 \%$ & $6,0 \%$ & $78,4 \%$ & $21,6 \%$ & $100 \%$ \\
\hline NORTE & $93,8 \%$ & $6,3 \%$ & $81,8 \%$ & $18,2 \%$ & $100 \%$ \\
\hline SUDESTE & $96,7 \%$ & $3,3 \%$ & $89,4 \%$ & $10,6 \%$ & $100 \%$ \\
\hline SUL & $99,0 \%$ & $1,0 \%$ & $91,8 \%$ & $8,2 \%$ & $100 \%$ \\
\hline
\end{tabular}

Fonte: PJU e Censo Escolar-INEP

Em relação à existência de salas de professores o PJU apresenta uma oferta discretamente melhor quando comparado com a EJA. Conforme disposto no gráfico 11, nota-se que, em ambos os casos, a absoluta maioria das escolas as possuem. Contudo, não se pode deixar de considerar que há a necessidade de melhorias neste sentido, já que a existência de um espaço destinado aos educadores faz parte da infraestrutura básica da escola e podemos ver que 8,2\% das escolas que acolhem o PJU e 13,2\% daquelas em que existe a EJA, faltam salas destinadas aos docentes. 


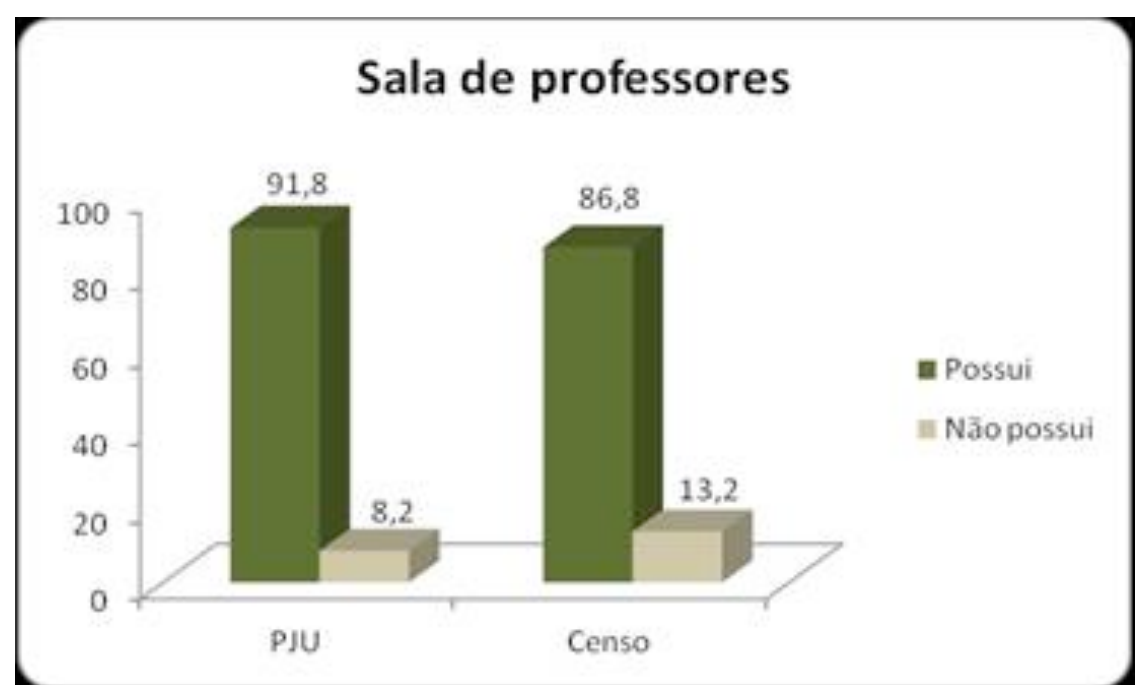

Gráfico 11. Existência de salas de professores nas escolas com JU e com EJA Fonte: PJU e Censo Escolar-INEP

Neste caso, mesmo no recorte regional, percebe-se maior equiparação da oferta entre a EJA e o PJU. Os dados da tabela 3 mostram que a região com melhor oferta de salas de professores nos dois casos é a sul, ao passo que a região nordeste, no caso da EJA é a que tem a menor oferta $(79,2 \%)$, ainda que mesmo nesta região a maioria das escolas disponibilizem as salas de reunião para os docentes.

Tabela 13

Existência de sala de reuniões para docentes nas escolas por região

\begin{tabular}{|l|l|l|l|l|l|}
\hline \multirow{2}{*}{ REGIÃO } & \multicolumn{2}{|l|}{ EJA } & PJU & \multirow{2}{*}{ Total } \\
\cline { 2 - 5 } & Possui & Não possui & Possui & Não possui & \\
\hline CENTRO-OESTE & $93,0 \%$ & $7,0 \%$ & $92,0 \%$ & $8,0 \%$ & $100 \%$ \\
\hline NORDESTE & $79,2 \%$ & $20,8 \%$ & $88,8 \%$ & $11,2 \%$ & $100 \%$ \\
\hline NORTE & $85,2 \%$ & $14,8 \%$ & $88,2 \%$ & $11,8 \%$ & $100 \%$ \\
\hline SUDESTE & $91,4 \%$ & $8,6 \%$ & $93,6 \%$ & $6,4 \%$ & $100 \%$ \\
\hline SUL & $97,2 \%$ & $2,8 \%$ & $95,9 \%$ & $4,1 \%$ & $100 \%$ \\
\hline
\end{tabular}

Fonte: PJU e Censo Escolar-INEP

A oferta de alimentação escolar aos alunos foi o útlimo item considerado passível de comparação entre o PJU e o Censo Escolar. Neste caso, ambos os cenários apresentam praticamente os mesmos índices. Conforme se vê no gráfico 12, 91,8\% das escolas que oferecem o PJU e 94,6\% das escolas que oferecem EJA disponibilizam a alimentação escolar para os alunos. Os percentuais são altos, apesar de ainda deixarem uma margem de deficiência na oferta. Trata-se de mais um dentre os vários aspectos que precisam ser aprimorados nas políticas públicas de educação de jovens e adultos, sobretudo se considerarmos que esta modalidade de ensino encontra-se hoje integrada à educação básica e amparada pela legislação vigente, que estabelece a obrigatoriedade da oferta de alimentação escola e prevê financiamento através do Programa Nacional de Alimentação Escolar. 


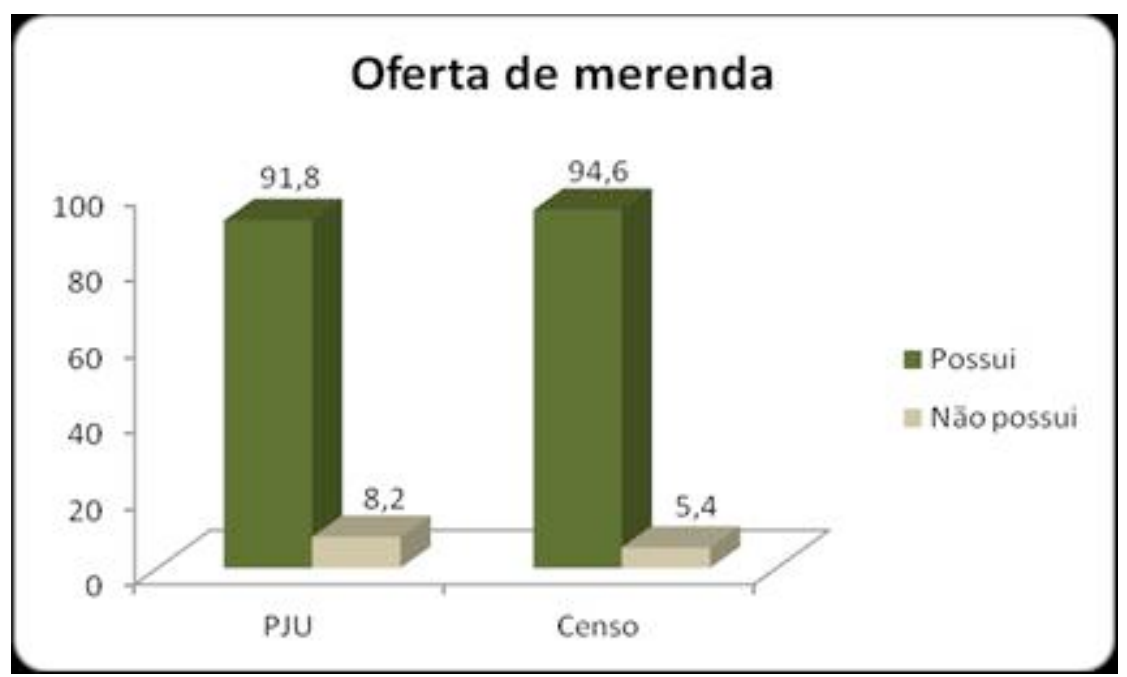

Gráfico 12. Oferta de merenda escolar pelas escolas com PJU e com EJA Fonte: PJU e Censo Escolar-INEP

Em relação à oferta de merenda escolar, no recorte regional, pode-se perceber pela tabela 14 que nas regiões centro-oeste, nordeste e norte os percentuais de oferta da EJA são maiores que os do PJU. No entanto a situação se inverte nas regiões sodeste e sul onde os percentuais de oferta do PJU se mostram mais altos.

Tabela 14

Existência de merenda nas escolas por região

\begin{tabular}{|l|l|l|l|l|l|}
\hline \multirow{2}{*}{ REGIÃO } & EJA & \multicolumn{2}{l|}{ PJU } & \multirow{2}{*}{ Total } \\
\cline { 2 - 5 } & Possui & Não possui & Possui & Não possui & \\
\hline CENTRO-OESTE & $96,5 \%$ & $3,5 \%$ & $96,0 \%$ & $4,0 \%$ & $100 \%$ \\
\hline NORDESTE & $96,2 \%$ & $3,8 \%$ & $83,6 \%$ & $16,4 \%$ & $100 \%$ \\
\hline NORTE & $98,4 \%$ & $1,6 \%$ & $80,0 \%$ & $20,0 \%$ & $100 \%$ \\
\hline SUDESTE & $91,2 \%$ & $8,8 \%$ & $97,6 \%$ & $2,4 \%$ & $100 \%$ \\
\hline SUL & $94,1 \%$ & $5,9 \%$ & $100,0 \%$ &, $0 \%$ & $100 \%$ \\
\hline
\end{tabular}

Fonte: PJU e Censo Escolar-INEP

\section{Considerações finais}

Os dados apresentados indicam algumas diferenciações ligadas à oferta do PJU em relação ao restante da EJA nos municípios analisados. Estas diferenciações, por sua vez, parecem apontar para certos efeitos sociais da inserção do programa sobre os diversos indivíduos envolvidos, sejam eles alunos, docentes ou gestores locais. O programa parece atrair de forma diferenciada jovens do sexo feminino. A este respeito seria interessante um aprofundamento das investigações no sentido de se compreender por que tal tendência se manifesta no PJU. Da mesma forma, o programa também atraiu jovens professores, sem experiência ou com pouca ainda. Nota-se, portanto, um efeito do programa nos municípios, na medida em que pode representar uma ampliação do mercado de trabalho, ao mesmo tempo em que se configura em uma oportunidade de formação inicial e continuada de professores. Outras informações sobre os docentes do PJU foram colhidas em várias 
ocasiões, através de variados métodos e instrumentos de coleta e podem contribuir para investigações futuras que venham a elucidar as ocorrências aqui apontadas.

Em relação aos possíveis efeitos do programa sobre a infraestrutura disponibilizada para os alunos, cabem também algumas colocações. Em primeiro lugar, há que se reconhecer que as diferenciações encontradas são, em sua maioria, sutis. Estas diferenciações não favorecem o PJU quando comparado com o restante da EJA na maioria dos aspectos analisados. Assim, os percentuais de oferta de biblioteca, Internet, TV, DVD ou VHS e alimentação escolar se mostraram abaixo dos apontados na EJA pelo Censo Escolar do INEP. Apenas os percentuais referentes à disponibilização do laboratório de informática e da sala de professores foram maiores no PJU. Contudo, reiteramos a ponderação sobre o fato de que o Censo Escolar apenas indica a existência ou inexistência do item, enquanto o PJU o considera existente com base na disponibilidade de uso pelos alunos. Este procedimento qualifica um pouco mais a informação e fornece mais elementos para uma avaliação da qualidade da oferta educacional.

Para um melhor entendimento acerca dos efeitos do PJU sobre a oferta de EJA nos municípios, abordagens qualitavas precisam estar vinculadas às análises dos dados quantativos existentes. Somente a partir de uma perspectiva qualitativa se torna possível compreender de formas mais aprofundada as razões pelas quais foram encontrados alguns dos índices aqui expostos, como é o caso da maior presença de jovens do sexo feminino no PJU, ou da maior quantidade de professores jovens e com pouca experiência docente no programa. Da mesma forma, um estudo aprofundado e detalhado se faz necessário para se responder se as características apresentadas Pelo PJU em relação ao restante da EJA nos municípios pesquisados possuem relação com o modelo de descentralização executiva e de cooperação entre os entes federativos. Neste sentido será de grande importância procurar compreender em que medida as conjunturas locais e a trajetória dos municípios na elaboração e execução de políticas públicas de juventude afeta a execução de programas Federais como o PJU. 


\section{Referências}

Abramo, H. W. (1997) . Considerações sobre a tematização social da juventude no Brasil. Revista Brasileira de Educação. Mai/Jun/Jul/Ago 1997 n. ${ }^{\circ}$ 5. Set/Out/Nov/Dez 1997 n. ${ }^{\circ}$ 6. Número especial

Arretche, M. (2003). Dossiê agenda de pesquisa em políticas públicas. Revista Brasileira de Ciências Sociais, São Paulo, v. 18, n. 51, p. 7-9.

Haddad, S. (2007) A ação de governos locais na educação de jovens e adultos. Revista Brasileira de Educação, vol.12, no.35, p.197-211.

Krawczyk, N. R.E Moraes, R. C. C. (2003) Entrevista com Hugo Zemelmam in Educ. Soc., Campinas, vol. 24, n. 82, p. 311-320, abril 2003 Disponível em http://www.cedes.unicamp.br

León Dávila, O. (2008) Institucionalidad y políticas de juventud. In: Revista Observatorio de Juventud, n. 19. Santiago: Instituto Nacional de la Juventud de Chile..

Novaes, R. Juventude e sociedade: jogos de espelhos, sentimentos, percepções e demandas por direitos e políticas públicas. Revista Sociologia Especial: Ciência, São Paulo, v. 1, n. 2, p. 110

Nóvoa, A. (2005). Vers un comparatisme critique. Regards sur l'éducation. Lisboa: Educa

Sposito, M. P; Carvalho E Silva, H. H. de; Souza, N A de. (2006) Juventude e poder local: um balanço de iniciativas públicas voltadas para jovens em municípios de regiões metropolitanas. Revista Brasileira de Educação, Rio de Janeiro, v. 11, n. 32, 


\section{Eliane Ribeiro Andrade}

\section{Sobre os Autores}

elianeribeiro@domain.com.br

Doutora em Educação pela Universidade Federal Fluminense - UFF, mestre em Educação pelo Instituto de Estudos Avançados em Educação-IESAE, da Fundação Getúlio Vargas - FGV e pósgraduada em Avaliação de Programas Sociais e Educativos pelo International Development Research Center e Instituto Interamericano de Cooperação para a Agricultura. Atualmente é professora do Programa de Pós-graduação em Educação da Universidade Federal do Estado do Rio de Janeiro-UNIRIO e professora da Faculdade de Educação da Universidade do Estado do Rio de Janeiro-UERJ. Tem experiência na área da educação, atuando principalmente nos seguintes temas: educação de jovens e adultos, juventude, movimentos sociais e políticas públicas, com ênfase na pesquisa e avaliação.

\section{Luiz Carlos de Souza}

lucarso@hotmail.com

Possui graduação em História pela Universidade Federal de Minas Gerais (2001). Mestrado em Educação Pela Universidade Federal de Minas Gerais, na linha de Avaliação de Políticas Públicas em Educação (2007). Atuou como pesquisador da Universidade Federal de Minas Gerais, no ProJovem - Programa Nacional de Inclusão de Jovens (2005 - 2007). Atualmente é pesquisador da Universidade Federal do Estado do Rio de Janeiro (UNIRIO), pelo Projovem Urbano, professor da Universidade Cândido Mendes/RJ e doutorando do programa de pós-graduação da Pontifícia Universidade Católica do Rio de Janeiro. Tem experiência na área de Educação, com ênfase em Gestão Educacional, Avaliação de Sistemas, Instituições, Planos e Programas Educacionais.

\section{Maria Virgínia de Freitas}

magi.freitas@acaoeducativa.org

Possui mestrado em Educação pela Universidade de São Paulo(1995). Atualmente é Coordenadora de Programa da Ação Educativa. Atuando principalmente nos seguintes temas: juventude, ensino supletivo

\section{Sandra Regina Sales}

\section{Sobre as Editoras Convidadas}

Professora do Programa de Pós-Graduação em Educação, Contextos Contemporâneos e Demandas Populares (PPGEduc) na linha de pesquisa Educação e Diversidades Étnico-Raciais e do Departamento Educação e Sociedade da Universidade Federal Rural do Rio de janeiro. sandrasales@ufrrj.br

Pesquisadora nos campos da Educação de Jovens e Adultos, Mídia e Educação e Políticas de Ação Afirmativa no Ensino Superior. Integra o Grupo de Pesquisa (CNPq) Políticas de trans-formação: pesquisas em educação e comunicação, do qual é líder, e o Laboratório de Estudos Afro-brasileiros - LEAFRO. Atualmente desenvolve as pesquisas $A E J A$ e a diversidade na mídia: uma análise das representações dos sujeitos, dos atores e das políticas educacionais nas revistas semanais brasileiras e Que educação para que cidadão? Discursos influentes na Educação de Jovens e Adultos no Brasil (1995-2013). É co-organizadora do livro Educação de Jovens e Adultos: políticas e práticas educativas (2011) e tem publicado artigos em revistas e capítulos de livros nas áreas de pesquisa nas quais atua. 


\section{Jane Paiva}

Professora do Programa de Pós-Graduação em Educação (ProPEd), na Linha de Pesquisa Educação Inclusiva e Processos Educacionais e do Curso de Pedagogia da Faculdade de Educação da Universidade do Estado do Rio de Janeiro (UERJ).

janepaiva@terra.com.br

Pesquisadora no campo da educação de jovens e adultos, atuando na formação de pedagogos e de novos pesquisadores - mestres e doutores. É líder do Grupo de Pesquisa (CNPq) Aprendizados ao longo da vida: sujeitos, políticas e processos educativos. No momento desenvolve a pesquisa integrada (com a Universidade Estadual de Campinas e a Universidade Federal de Juiz de Fora) Diagnóstico da qualidade de ensino na educação de jovens e adultos: um estudo de caso nos municípios de Campinas, Juiz de Fora e Rio de Janeiro, financiada pelo Edital Observatório da Educação, da CAPES/INEP; e coordena as ações do projeto de pesquisa e extensão do Centro de Referência e Memória da Educação Popular e da Educação de Jovens e Adultos (CReMEJA). Autora de artigos em revistas e capítulos de livros no campo.

\begin{tabular}{|c|c|c|}
\hline \multicolumn{3}{|c|}{ DOSSIÊ EJA II } \\
\hline \multicolumn{3}{|c|}{ arquivos analíticos de políticas educativas } \\
\hline Volume 22 Número 60 & 30 de junho de 2014 & ISSN 1068-2341 \\
\hline
\end{tabular}

\footnotetext{
(C)

SORERTIGHIS RESERVED O Copyright e retido pelo/a o autor/a (ou primeiro co-autor) que outorga o direito da primeira publicação à revista Arquivos Analíticos de Políticas Educativas. Más informação da licença de Creative Commons encontram-se em http://creativecommons.org/licenses/by-nc-nd/2.5. Qualquer outro uso deve ser aprovado em conjunto pelo/s autor/es e por AAPE/EPAA. AAPE/EPAA é publicada por Mary Lou Fulton Institute Teachers College da Arizona State University. Os textos publicados em AAPE são indexados por CIRC (Clasificación Integrada de Revistas Científicas, Espanha) DIALNET (Espanha),Directory of Open Access Journals, Education Full Text (H.W. Wilson), EBSCO Education Research Complete, , ERIC, , QUALIS A2 (Brasil), SCImago Journal Rank; SCOPUS, SOCOLAR (China). Contribua com comentários e sugestões a http://epaa.info/wordpress/ ou para Gustavo E. Fischman fischman@asu.edu.
}

Curta a nossa comunidade EPAA's Facebook https://www.facebook.com/EPAAAAPE e Twitter feed@epaa_aape. 


\section{arquivos analíticos de políticas educativas conselho editorial}

Editor: Gustavo E. Fischman (Arizona State University) Editores Associados: Rosa Maria Bueno Fisher e Luis A. Gandin

(Universidade Federal do Rio Grande do Sul)

Dalila Andrade de Oliveira Universidade Federal de Minas Gerais, Brasil

Paulo Carrano Universidade Federal Fluminense, Brasil

Alicia Maria Catalano de Bonamino Pontificia Universidade Católica-Rio, Brasil

Fabiana de Amorim Marcello Universidade Luterana do Brasil, Canoas, Brasil

Alexandre Fernandez Vaz Universidade Federal de Santa Catarina, Brasil

Gaudêncio Frigotto Universidade do Estado do Rio de Janeiro, Brasil

Alfredo M Gomes Universidade Federal de Pernambuco, Brasil

Petronilha Beatriz Gonçalves e Silva Universidade Federal de São Carlos, Brasil

Nadja Herman Pontificia Universidade Católica -Rio Grande do Sul, Brasil

José Machado Pais Instituto de Ciências Sociais da Universidade de Lisboa, Portugal

Wenceslao Machado de Oliveira Jr. Universidade Estadual de Campinas, Brasil
Jefferson Mainardes Universidade Estadual de Ponta Grossa, Brasil

Luciano Mendes de Faria Filho Universidade Federal de Minas Gerais, Brasil

Lia Raquel Moreira Oliveira Universidade do Minho, Portugal

Belmira Oliveira Bueno Universidade de São Paulo, Brasil

António Teodoro Universidade Lusófona, Portugal

Pia L. Wong California State University Sacramento, U.S.A

Sandra Regina Sales Universidade Federal Rural do Rio de Janeiro, Brasil

Elba Siqueira Sá Barreto Fundação Carlos Chagas, Brasil

Manuela Terrasêca Universidade do Porto, Portugal

Robert Verhine Universidade Federal da Bahia, Brasil

Antônio A. S. Zuin Universidade Federal de São Carlos, Brasil 


\section{education policy analysis archives editorial board}

Editor Gustavo E. Fischman (Arizona State University)

Associate Editors: Audrey Amrein-Beardsley (Arizona State University), Rick Mintrop, (University of California, Jeanne M. Powers (Arizona State University)

Jessica Allen University of Colorado, Boulder

Gary Anderson New York University

Michael W. Apple University of Wisconsin, Madison

Angela Arzubiaga Arizona State University

David C. Berliner Arizona State University

Robert Bickel Marshall University

Henry Braun Boston College

Eric Camburn University of Wisconsin, Madison

Wendy C. Chi* University of Colorado, Boulder

Casey Cobb University of Connecticut

Arnold Danzig Arizona State University

Antonia Darder University of Illinois, UrbanaChampaign

Linda Darling-Hammond Stanford University

Chad d'Entremont Strategies for Children

John Diamond Harvard University

Tara Donahue Learning Point Associates

Sherman Dorn University of South Florida

Christopher Joseph Frey Bowling Green State University

Melissa Lynn Freeman* Adams State College

Amy Garrett Dikkers University of Minnesota

Gene V Glass Arizona State University

Ronald Glass University of California, Santa Cruz

Harvey Goldstein Bristol University

Jacob P. K. Gross Indiana University

Eric M. Haas WestEd

Kimberly Joy Howard* University of Southern California

Aimee Howley Ohio University

Craig Howley Ohio University

Steve Klees University of Maryland

Jaekyung Lee SUNY Buffalo
Christopher Lubienski University of Illinois, UrbanaChampaign

Sarah Lubienski University of Illinois, UrbanaChampaign

Samuel R. Lucas University of California, Berkeley

Maria Martinez-Coslo University of Texas, Arlington

William Mathis University of Colorado, Boulder

Tristan McCowan Institute of Education, London

Heinrich Mintrop University of California, Berkeley

Michele S. Moses University of Colorado, Boulder

Julianne Moss University of Melbourne

Sharon Nichols University of Texas, San Antonio

Noga O'Connor University of Iowa

João Paraskveva University of Massachusetts, Dartmouth

Laurence Parker University of Illinois, UrbanaChampaign

Susan L. Robertson Bristol University

John Rogers University of California, Los Angeles

A. G. Rud Purdue University

Felicia C. Sanders The Pennsylvania State University

Janelle Scott University of California, Berkeley

Kimberly Scott Arizona State University

Dorothy Shipps Baruch College/CUNY

Maria Teresa Tatto Michigan State University

Larisa Warhol University of Connecticut

Cally Waite Social Science Research Council

John Weathers University of Colorado, Colorado Springs

Kevin Welner University of Colorado, Boulder

Ed Wiley University of Colorado, Boulder

Terrence G. Wiley Arizona State University

John Willinsky Stanford University

Kyo Yamashiro University of California, Los Angeles

* Members of the New Scholars Board 


\section{archivos analíticos de políticas educativas consejo editorial}

Editor: Gustavo E. Fischman (Arizona State University)

Editores. Asociados Alejandro Canales (UNAM) y Jesús Romero Morante (Universidad de Cantabria)

Armando Alcántara Santuario Instituto de Investigaciones sobre la Universidad y la Educación, UNAM México

Claudio Almonacid Universidad Metropolitana de Ciencias de la Educación, Chile

Pilar Arnaiz Sánchez Universidad de Murcia, España

Xavier Besalú Costa Universitat de Girona, España

Jose Joaquin Brunner Universidad Diego Portales, Chile

Damián Canales Sánchez Instituto Nacional para la Evaluación de la Educación, México

María Caridad García Universidad Católica del Norte, Chile

Raimundo Cuesta Fernández IES Fray Luis de León, España

Marco Antonio Delgado Fuentes Universidad Iberoamericana, México

Inés Dussel FLACSO, Argentina

Rafael Feito Alonso Universidad Complutense de Madrid, España

Pedro Flores Crespo Universidad Iberoamericana, México

Verónica García Martínez Universidad Juárez Autónoma de Tabasco, México

Francisco F. García Pérez Universidad de Sevilla, España

Edna Luna Serrano Universidad Autónoma de Baja California, México

Alma Maldonado Departamento de Investigaciones Educativas, Centro de Investigación y de Estudios Avanzados, México

Alejandro Márquez Jiménez Instituto de Investigaciones sobre la Universidad y la Educación, UNAM México

José Felipe Martínez Fernández University of California Los Angeles, USA
Fanni Muñoz Pontificia Universidad Católica de Perú

Imanol Ordorika Instituto de Investigaciones Economicas - UNAM, México

Maria Cristina Parra Sandoval Universidad de Zulia, Venezuela

Miguel A. Pereyra Universidad de Granada, España

Monica Pini Universidad Nacional de San Martín, Argentina

Paula Razquin UNESCO, Francia

Ignacio Rivas Flores Universidad de Málaga, España

Daniel Schugurensky Arizona State University

Orlando Pulido Chaves Universidad Pedagógica Nacional, Colombia

José Gregorio Rodríguez Universidad Nacional de Colombia

Miriam Rodríguez Vargas Universidad Autónoma de Tamaulipas, México

Mario Rueda Beltrán Instituto de Investigaciones sobre la Universidad y la Educación, UNAM México

José Luis San Fabián Maroto Universidad de Oviedo, España

Yengny Marisol Silva Laya Universidad Iberoamericana, México

Aida Terrón Bañuelos Universidad de Oviedo, España

Jurjo Torres Santomé Universidad de la Coruña, España

Antoni Verger Planells University of Amsterdam, Holanda

Mario Yapu Universidad Para la Investigación Estratégica, Bolivia 